\title{
The Tangled Web of Non-Canonical Wnt Signalling in Neural Migration
}

\author{
Charlotte E.J. Clark C. Cathrin Nourse Helen M. Cooper \\ Queensland Brain Institute, University of Queensland, Brisbane, Qld., Australia
}

\section{Key Words}

Wnt $\cdot$ Ror $\cdot$ Ryk $\cdot$ Non-canonical Wnt signalling $\cdot$ Neural

tube formation $\cdot$ Convergent extension $\cdot$ Axon guidance

\begin{abstract}
In all multicellular animals, successful embryogenesis is dependent on the ability of cells to detect the status of the local environment and respond appropriately. The nature of the extracellular environment is communicated to the intracellular compartment by ligand/receptor interactions at the cell surface. The Wnt canonical and non-canonical signalling pathways are found in the most primitive metazoans, and they play an essential role in the most fundamental developmental processes in all multicellular organisms. Vertebrates have expanded the number of Wnts and Frizzled receptors and have additionally evolved novel Wnt receptor families (Ryk, Ror). The multiplicity of potential interactions between Wnts, their receptors and downstream effectors has exponentially increased the complexity of the signal transduction network. Signalling through each of the Wnt pathways, as well as crosstalk between them, plays a critical role in the establishment of the complex architecture of the vertebrate central nervous system. In this review, we explore the signalling networks triggered by non-canonical Wnt/receptor interactions, focussing on the emerging roles of the non-conventional Wnt receptors Ryk and Ror. We describe the role of these pathways in neural tube formation and axon guidance where Wnt signalling controls tissue polarity, coordinated cell migration and axon guidance via remodelling of the cytoskeleton.

Copyright ๑ 2012 S. Karger AG, Basel
\end{abstract}

\section{A Brief History of Wnt Signalling}

In all multicellular animals, complex developmental processes such as axis formation, tissue specification and polarity must be tightly coordinated in space and time if a functional organism is to be produced. Successful embryogenesis is dependent on the ability of cells within developing tissues to sense the status of their local environment and to respond to the relevant signals by initiating the appropriate cellular response. In all metazoans, including the simplest multicellular organisms, the nature of the extracellular environment is communicated to the intracellular compartment by cytoplasmic signal transduction cascades activated by ligand-receptor interactions at the cell surface. Sequencing of genomes from extant, primitive multicellular organisms such as sponges has led to the hypothesis that essential developmental signal transduction pathways, including the Wnt, sonic hedgehog and transforming growth factor $\beta$ pathways, originally evolved in the earliest multicellular organisms [1].

The Wnt family of extracellular ligands, through their cell surface receptors (Frizzled, Fz; Ryk, Ror), activate several distinct, but integrated, signal transduction pathways that have diverse developmental consequences (fig. 1). The canonical (Wnt/ $\beta$-catenin) pathway regulates stem cell proliferation and self-renewal, cell fate determination and axis formation by modulating gene expression. The non-canonical planar cell polarity (PCP) pathway controls the remodelling of the cytoskeleton via a $\beta$-catenin-independent mechanism and controls tissue polarity, coordinated cell migration and axon guidance.

\section{KARGER \\ Fax +4161306 1234 \\ E-Mail karger@karger.ch}

www.karger.com
(C) 2012 S. Karger AG, Basel

1424-862X/12/0203-0202\$38.00/0

Accessible online at:

www.karger.com/nsg
Helen M. Cooper

Queensland Brain Institute

University of Queensland

Brisbane, QLD 4072 (Australia)

Tel. +61 73346 6354, E-Mail h.cooper@uq.edu.au 
The $\mathrm{Wnt} / \mathrm{Ca}^{2+}$ pathway regulates cell fate determination, cell migration, axon guidance and also collaborates with the PCP pathway in regulating tissue polarity. Key components of the Wnt/ $\beta$-catenin pathway have been identified in the sponge Amphimedon queenslandica, a member of the oldest known extant animal phylum, thereby implicating this pathway in embryonic axis patterning at a very early evolutionary time point [2]. These components include Wnt, Fz, low-density lipoprotein receptorrelated protein 5/6 (LRP5/6), Dishevelled (Dvl in mammals, Dsh in Drosophila and Xenopus), axin, adenomatous polyposis coli (APC), glycogen synthase kinase $3 \beta$ (GSK3 $\beta$ ) and T cell factor (TCF) (fig. 1). The non-canonical PCP and $\mathrm{Wnt} / \mathrm{Ca}^{2+}$ pathways are believed to have evolved after the divergence of sponges and the eumetazoan lineage in which animals display radial or bilateral symmetry (sea anemones or jellyfish, respectively) $[1,2]$.

Both nematodes and insects utilise the $\mathrm{Wnt} / \beta$-catenin, PCP and $\mathrm{Wnt} / \mathrm{Ca}^{2+}$ pathways and have additionally evolved new coreceptors and novel Wnt receptor families (Ryk and Ror) which are able to potentiate or suppress these pathways, depending on the biological context. In addition, gene duplication has expanded the number of Wnt ligands (19 in mammals) and receptors (10 Fzs in mammals) [3]. Thus, the multiplicity of potential interactions between Wnts, their receptors and downstream effectors has exponentially increased the complexity of the signal transduction network. In the context of nervous system development, the functional outcome of Wnt pathway activation has been conserved across all species. Signalling through each of the Wnt pathways, as well as crosstalk between them, plays a critical role in all facets of nervous system development, including neural induction, neuronal polarisation, cell migration, axon and dendritic growth, axon guidance and synaptogenesis [4-8].

In this review, we explore the signalling networks triggered by non-canonical Wnt/receptor interactions, focussing on the emerging roles of the non-conventional Wnt receptors Ryk and Ror. It has taken 25 years to unravel the complexities of the Fz-dependent pathways. In contrast, characterisation of the Ryk and Ror signalling cascades is in its infancy. What is becoming clear, however, is that none of these pathways operate in isolation. Instead, evidence is emerging that there is a great deal of crosstalk between them. Here, we focus on the role of Wnt signalling in the establishment of the complex architecture of the vertebrate central nervous system (CNS). In particular we concentrate on those aspects of CNS development (neural tube formation and axon guidance) where a clearer picture of the function of the non-canonical receptors

Non-Canonical Wnt Signalling in Neural Migration
Ryk and Ror is beginning to emerge. In order to understand the relevance of Ryk and Ror signalling in the context of the entire Wnt signalling network, we start with an abridged summary of the major Wnt pathways.

\section{Canonical and Non-Canonical Wnt Pathways}

Mammalian Wnts can be subdivided into two classes, originally defined by their ability to act as oncogenes [9]. The transforming Wnts (e.g. Wnt1, Wnt3) activate the canonical Wnt/ $\beta$-catenin pathway, whereas the non-transforming Wnts (e.g. Wnt4, Wnt5a, Wnt11) act through the non-canonical ( $\beta$-catenin-independent) pathways. Wnts signal via the $\mathrm{Fz}$ receptors [10-12] which can also be loosely classified into canonical or non-canonical receptors, depending on whether or not they prevent $\beta$-catenin degradation and trigger its translocation to the nucleus. Fzs are members of the 7-pass transmembrane domain, G-protein-coupled receptor family. The extracellular cysteine-rich domain is responsible for Wnt binding [13] and other extracellular subdomains are involved in coreceptor binding (e.g. binding to the coreceptor Van Gogh [14]). The cytoplasmic domain comprises 3 intracellular loops and a C-terminal tail that associates with a variety of downstream effectors [15]. In all Wnt pathways, Dvl is recruited to $\mathrm{Fz}$ at the membrane (fig. 1) and activated by phosphorylation after Wnt binding and is therefore perfectly positioned to regulate crosstalk between pathways [16]. The N-terminal and central PDZ domains of Dvl are required for $\mathrm{Wnt} / \beta$-catenin signalling, whereas the $\mathrm{PDZ}$ and C-terminal regions activate the PCP pathway [16].

\section{The Wnt/ $\beta$-Catenin Pathway}

In the absence of canonical Wnt binding, cytoplasmic $\beta$-catenin is captured by the destruction complex (containing the scaffold protein axin and the tumour suppressor gene APC) where it is phosphorylated by GSK3 $\beta$ and casein kinase $1 \alpha(\mathrm{CK} 1 \alpha)$ and targeted for degradation in the proteasome (fig. 1). Upon canonical Wnt binding, Fz forms a coreceptor complex with LRP5/6, resulting in the recruitment of $\mathrm{Dvl}$ and components of the destruction complex to the receptor. GSK3 $\beta$ - and CK $1 \alpha$ mediated phosphorylation of $\beta$-catenin is subsequently inhibited, preventing degradation of $\beta$-catenin which is then free to translocate into the nucleus where it forms a transcriptional activation complex with TCF. This leads to the transcription of target genes involved in embryonic patterning and cell fate specification and proliferation [for detailed reviews, see 17, 18]. 


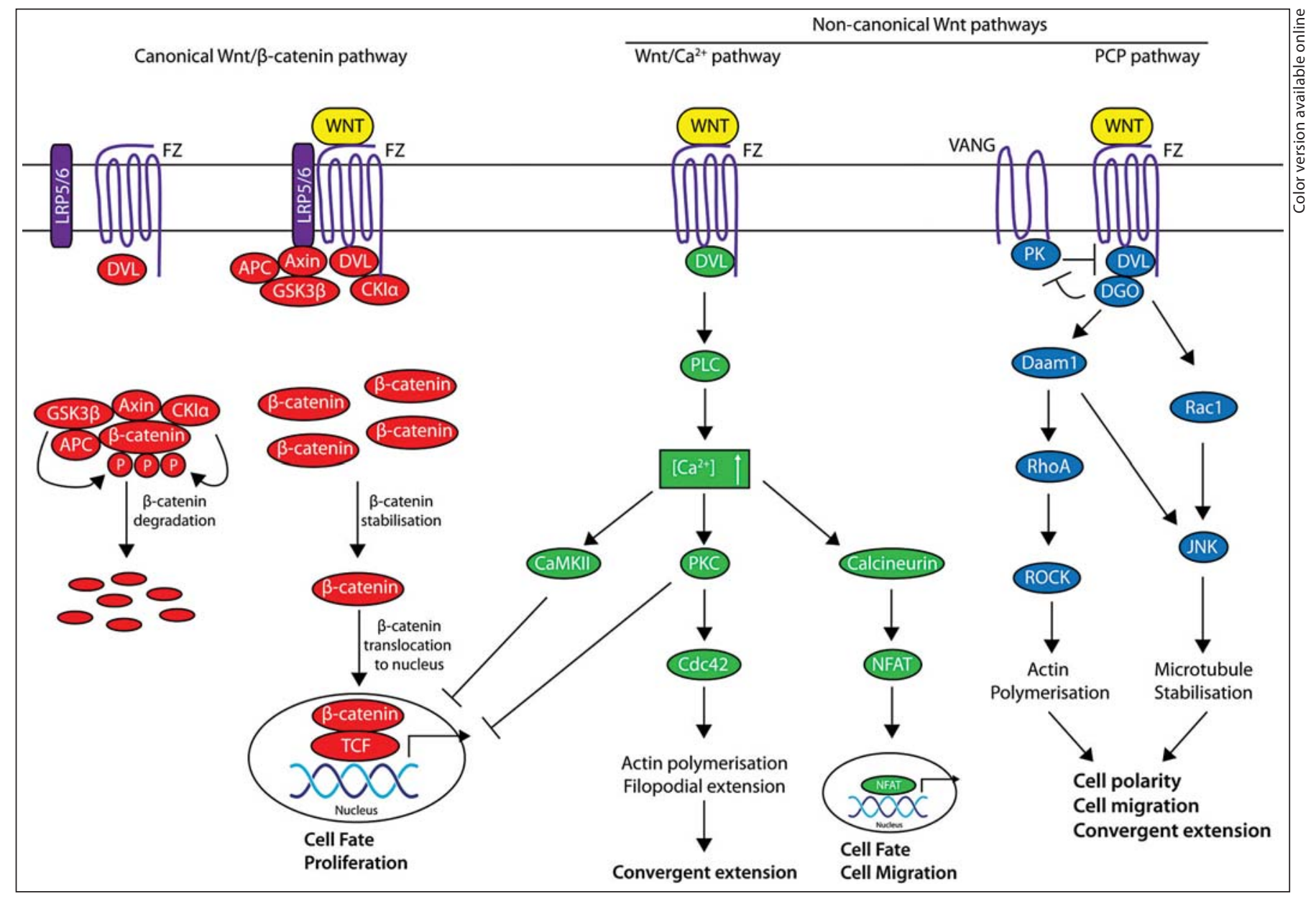

Fig. 1. Wnt signalling pathways. In the canonical Wnt/ $\beta$-catenin pathway in the absence of a Wnt ligand, $\beta$-catenin is recruited by the destruction complex and phosphorylated by glycogen synthase kinase $3 \beta$ (GSK $3 \beta)$ and casein kinase I $\alpha$ (CKI $\alpha)$ targeting it for degradation in the proteasome; levels of cytosolic $\beta$-catenin are subsequently kept low. In the presence of a Wnt ligand, members of the destruction complex are recruited to the membrane, and $\beta$-catenin accumulates within the cytoplasm. $\beta$-Catenin then translocates to the nucleus where it affects $\mathrm{T}$ cell factor (TCF) transcription controlling cell fate and proliferation. The non-canonical Wnt/Ca ${ }^{2+}$ pathway leads to increased intracellular $\mathrm{Ca}^{2+}$

\section{The Non-Canonical PCP Pathway}

Non-canonical Wnt signalling is $\beta$-catenin independent and mediated by two distinct, but interacting pathways, the $\mathrm{Ca}^{2+}$-independent PCP pathway and the $\mathrm{Ca}^{2+}{ }_{-}$ dependent Wnt/Ca ${ }^{2+}$ pathway (fig. 1). The PCP pathway is best characterised in Drosophila where it is responsible for establishing tissue polarity during wing and eye formation [for a detailed review, see 19]. A similar mechanism regulates tissue polarity during gastrulation and neural tube formation in the vertebrate embryo. In contrast to the cell- which activates calcium calmodulin kinase II (CaMKII), protein kinase $\mathrm{C}$ (PKC) and calcineurin. CaMKII and PKC inhibit canonical Wnt signalling, $\mathrm{PKC}$ also activates $\mathrm{Cdc42}$ regulating cytoskeletal dynamics during convergent extension. Calcineurin activates NFAT which affects gene transcription controlling cell fate and cell migration. Non-canonical PCP signalling involves interactions between $\mathrm{Fz}$, Vang, $\mathrm{Pk}$ and Dgo with activation of RhoA and ROCK via Daam1, which leads to actin polymerisation, and Racl and JNK, which leads to microtubule stabilisation. This regulation of cytoskeletal dynamics controls cell polarity, cell migration and convergent extension.

autonomous function of the Wnt/ $\beta$-catenin pathway, $\mathrm{PCP}$ signalling in the fly wing epithelium requires interaction of pathway components on neighbouring cells. Upon activation of the pathway, the polarity signal is transmitted throughout the plane of the tissue through local cell-cell interactions. Prior to polarisation, the core PCP components are distributed uniformly around the plasma membrane. In the Drosophila wing epithelium, the two core PCP complexes are found on opposite sides of the polarising cell (fig. 2a). The distal core complex comprises Fz, 
Dsh (Dvl in mammals) and Diego (Dgo, diversin in mammals), whereas the strabismus/Van Gogh (Vang)-prickle $(\mathrm{Pk})$ complex is localised on the proximal side. Both complexes also contain the cadherin-like receptor, flamingo (Fmi, Celsr in mammals), which directly links the distal and proximal complexes on adjacent cells through transhomophilic adhesive interactions. The interaction between $\mathrm{Fz}$ in the signalling cell and Vang in the receiving cell triggers the asymmetric distribution of both core complexes in the receiving cell (fig. 2a). The polarised receiving cell then becomes the signalling cell and induces polarity in another neighbour. It is these reiterative local cell-cell interactions that transmit the planar polarity signal throughout the tissue. Fz-Vang interactions between cells are also required for the correct alignment of the polarised tissue relative to the body axis. Exactly how this global signal is propagated is not well understood; however, to date there is no convincing evidence in Drosophila that Wnts are involved [14]. In vertebrates the situation is different as Wnts are directly involved in activating Fz signalling in the context of planar polarity [20]. Moreover, a recent study has provided convincing evidence that global tissue polarity in the mouse embryo is established in response to a Wnt gradient [21].

Cell-autonomous versions of the PCP pathway drive cell migration, axon growth and pathfinding, synaptogenesis and ciliogenesis through modulation of the actin and microtubule cytoskeletons [4, 7, 20, 22-24] (fig. 1). In these situations non-canonical Wnts activate the PCP pathway through the recruitment of the cytoplasmic signalling components Dvl and Dgo to the cytoplasmic domain of Fz receptors. Here, Dgo activates Dvl by inhibiting the interaction of the Pk-Vang complex with Dvl (fig. 1). Daam1, a scaffold protein, links Dvl to RhoA, resulting in actin stress fibre formation $[16,22,25]$. Dvl also

Fig. 2. The PCP pathway establishes tissue polarity and drives convergent extension during neural tube formation. a Prior to polarisation in the fly wing epithelium, the core PCP components are distributed uniformly around the plasma membrane. Upon activation of PCP signalling, the interaction between $\mathrm{Fz}$ in the signalling cell and Vang in the receiving cell triggers the asymmetric distribution of both core complexes in the receiving cell. The polarised receiving cell then becomes the signalling cell and induces polarity in another neighbour. b During neurulation, the neuro-ectoderm migrates from the dorsolateral regions of the embryo towards the dorsal midline by mediolateral intercalation which drives convergent extension and neural tube formation. The PCP pathway polarises cells in the mediolateral direction, promoting mediolateral intercalation. $\mathrm{A}=$ Anterior; $\mathrm{D}=$ dorsal; $\mathrm{M}=$ medial; $\mathrm{V}=$ ventral.

Non-Canonical Wnt Signalling in Neural Migration

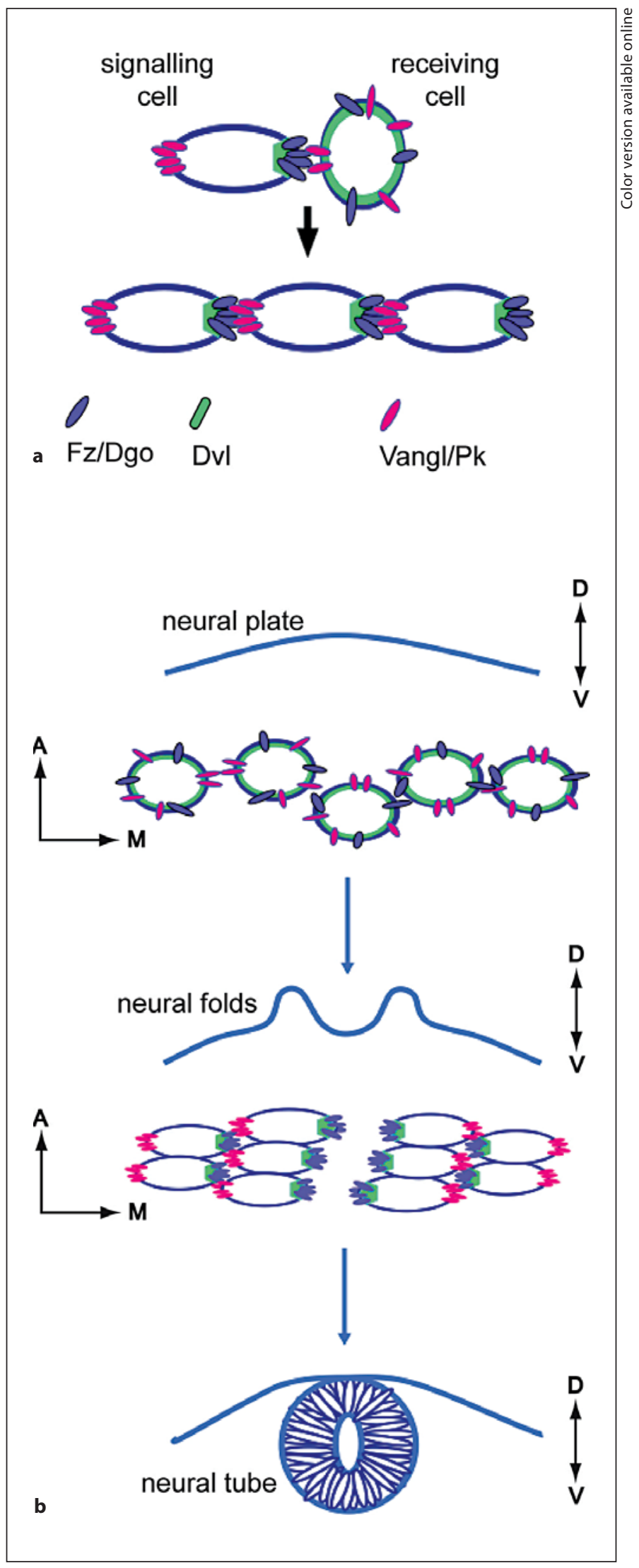

Neurosignals 2012;20:202-220 
activates Racl leading to the protrusion of actin-based lamellipodia and c-Jun-dependent transcription. Activation of Rac1, Cdc42 and JNK also leads to stabilisation of microtubule filaments $[16,22]$. Thus, direct interaction of Dvl with both RhoA and Racl is fundamental to the regulation of cell polarity through the remodelling of the actin and microtubule cytoskeletons.

One puzzle that arises when comparing the non-cellautonomous PCP pathway responsible for planar polarity, to the cell-autonomous PCP signalling governing processes such as axon guidance, has been the role of Vang. In the Drosophila wing, Vang (proximal core complex) and $\mathrm{Fz}$ (distal core complex) are localised on apposing cell membranes. The polarity signal initiated by intracellular adhesion between the core complexes is then transmitted intracellularly (from the proximal side) via Vang to the distal side of the same cell, where it induces polarised proximal localisation of the $\mathrm{Fz}$ complex (fig. 2a). Therefore, the initiation of cell polarity requires that $\mathrm{Fz}$ and Vang operate in apposing cells. In contrast, in axon growth cones $\mathrm{Fz}$ and Vang are always present on the same membrane, indicating a fundamental difference in the interaction between core PCP components. A recent study from the Zou laboratory may have, at least partially, solved this puzzle [23]. Previous studies had shown that Wnt activation of the PCP pathway requires that Fz be internalised through clathrin-mediated endocytosis [26]. Shafer et al. [23] now show that Vangl2 is highly enriched in the tips of growth cone filopodia and that, upon Wnt activation, it selectively promotes the internalisation of the non-phosphorylated, active form of Fz3, thereby focussing PCP pathway activation to a localised membrane domain. These very different modes of PCP signalling demonstrate the versatility of the core components and provide an explanation for why non-canonical signalling plays such a prominent role in many fundamental morphological processes during embryonic development.

\section{The Non-Canonical Wnt/Ca ${ }^{2+}$ Pathway}

The $\mathrm{Ca}^{2+}$-dependent branch of non-canonical Wnt signalling is important in cell fate determination, cell migration, convergent extension (CE) and axon guidance. During gastrulation and neural tube formation, it works in parallel with the PCP pathway through its ability to activate a distinct set of actin modulators. Receptor binding activates phospholipase $\mathrm{C}$ which in turn stimulates diacylglycerol and inositol triphosphate (IP3) production, leading to $\mathrm{Ca}^{2+}$ release from intracellular stores and the activation of the $\mathrm{Ca}^{2+}$-sensing enzymes, calcium calmodulin kinase II (CaMKII), calcineurin and protein kinase C (PKC) [27-30] (fig. 1). Localised increases in intracellular $\mathrm{Ca}^{2+}$ stimulate the formation of new filopodial protrusions via regulation of actin dynamics [31]. $\mathrm{Dvl}$ is also required for pathway activation as blocking Dvl function leads to decreased activation of PKC by Fz7 [29].

$\mathrm{Dvl}$ is a critical component of the Wnt/ $\beta$-catenin, PCP and $\mathrm{Wnt} / \mathrm{Ca}^{2+}$ pathways, placing it in an ideal position to regulate crosstalk between pathways. A Dvl mutant lacking the N-terminal DIX domain (Dsh $\Delta$ DIX) is sufficient to activate the PCP pathway but not the Wnt/ $\beta$-catenin pathway, which requires the DIX domain $[32,33]$. Dsh $\Delta$ DIX is also sufficient to activate the $\mathrm{Wnt} / \mathrm{Ca}^{2+}$ pathway via stimulation of $\mathrm{Ca}^{2+}$ fluxes and activation of $\mathrm{PKC}$ and CaMKII [29]. This modular functionality of Dvl provides a mechanism by which individual Wnt pathways can directly influence each other's activity. For example, $\mathrm{Wnt} / \mathrm{Ca}^{2+}$ signalling is able to antagonise $\mathrm{Wnt} / \beta$-catenin signalling during CE $[27,34-36]$. The $W n t / \beta$-catenin pathway is required indirectly for CE movements of mesodermal cells in the early Xenopus embryo through TCF-mediated transcriptional activation of Xnrl, a modulator of cell migration [34]. However, Wnt5- or Wnt11mediated Wnt $/ \mathrm{Ca}^{2+}$ pathway activation suppresses the Wnt/ $\beta$-catenin pathway at two levels (fig. 1). Dvl-dependent activation of PKC blocks Dvl-induced $\beta$-catenin function and Dvl-dependent activation of CaMKII inhibits TCF-mediated transcription (fig. 1). Thus, Dvl activates the $\mathrm{Wnt} / \mathrm{Ca}^{2+}$ pathway while simultaneously inhibiting the Wnt/ $\beta$-catenin pathway [34].

\section{The Non-Canonical Ror Pathway}

The non-canonical, $\beta$-catenin-independent Wnt receptors Ror1 and Ror2 are receptor tyrosine kinases required for the establishment of cell polarity, asymmetric cell division and cell migration during key morphological processes, including neural tube formation, testes development, and heart and bone formation [for a detailed review, see 37]. Vertebrate Rors possess an extracellular cysteine-rich domain (similar to that of Fz receptors) and a membrane proximal kringle domain. Within the cytoplasmic region there is an active tyrosine kinase domain and 2 serine/threonine-rich domains flanking a prolinerich domain. The extracellular cysteine-rich domain is responsible for the interaction of Ror receptors with Wnt ligands [38-40] and mediates the formation of a coreceptor complex with Fz2 [40]. The immunoglobulin-like domains may also be involved in receptor-ligand and receptor-coreceptor interactions [37]. The function of the krin- 


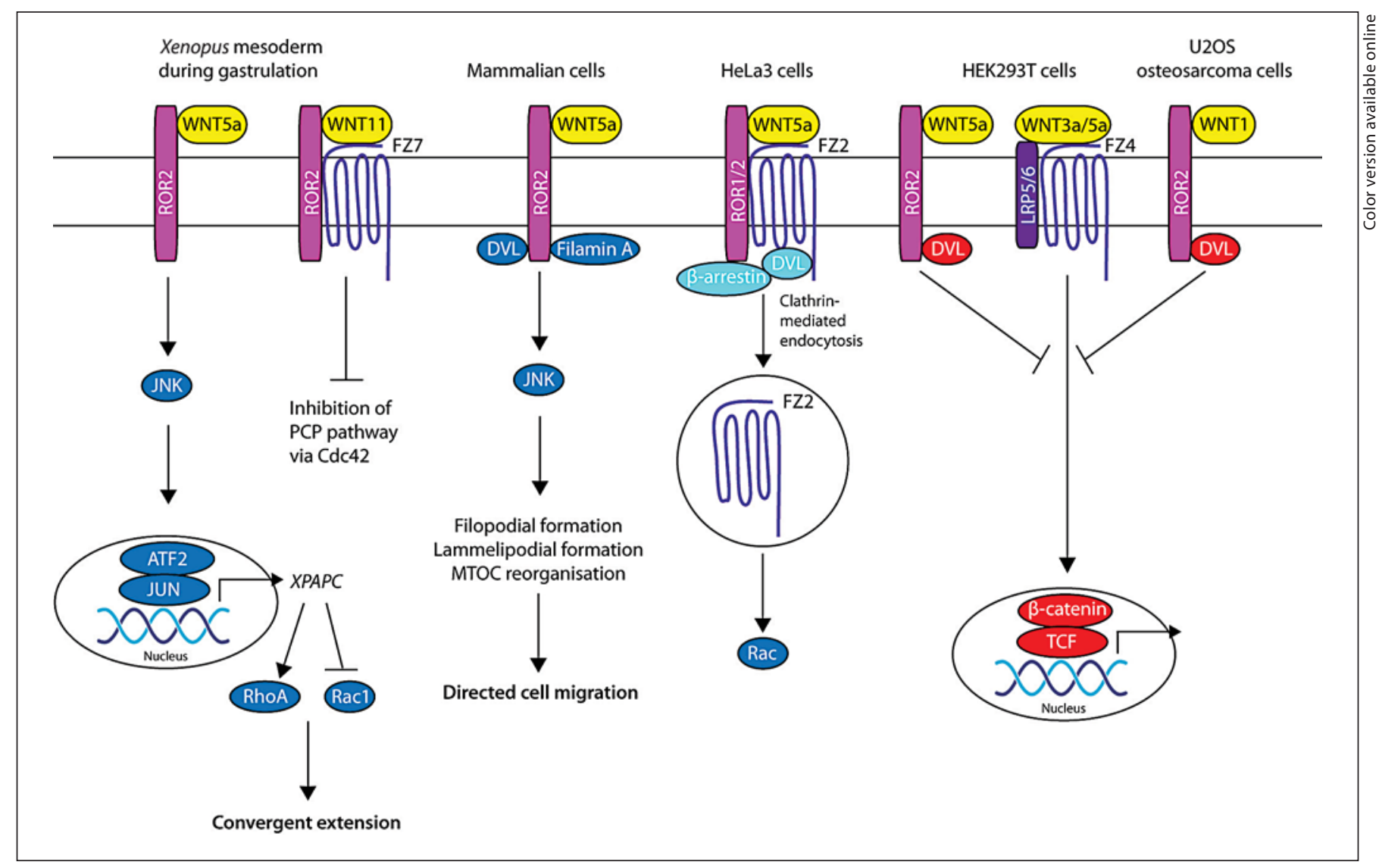

Fig. 3. Non-canonical Ror signalling. In Xenopus mesoderm during gastrulation, Wnt5a/Ror2 binding leads to activation of the PCP pathway affecting convergent extension. Conversely, Wnt11 activation of Ror2-Fz7 leads to inhibition of the PCP pathway. In mammalian cells [for specific cell types, see 113], Wnt5a activation of Ror2 leads to PCP pathway activation via recruitment of filamin A to the membrane controlling directed cell migration.

gle domain has not been determined but it is predicted to associate with intracellular signalling molecules. The serine/threonine-rich and proline-rich domains also enable binding to downstream effectors, including the scaffold protein filamin A, and serine/threonine and tyrosine kinases $[37,41]$. The tyrosine kinase domain is responsible for autophosphorylation and the phosphorylation of other intracellular effectors upon Wnt5a binding [42-44].

Non-canonical Wnt5a has been identified as the principal ligand for Ror1 and Ror2 on the basis that Wnt5a loss-of-function mice exhibit an array of phenotypes that closely parallel those seen in Ror knockout mice [45-48]. Upon Wnt5a binding, Ror2 promotes cell migration in a Dvl-dependent manner [41] (fig. 3). In a parallel pathway, the actin-binding protein filamin $\mathrm{A}$ is recruited to the Ror2 cytoplasmic domain, resulting in reorganisation of
In HeLa3 cells, Wnt5a/Ror2-Fz2 binding leads to recruitment of $\beta$-arrestin and Dvl and clathrin-mediated endocytosis of Fz2 which activates the PCP pathway. In HEK293 cells, Wnt3a/5a can activate TCF transcription via Fz4-LRP5/6. Wnt5a/Ror2 binding can inhibit this pathway, and in U2OS osteosarcoma cells Wnt1/ Ror2 binding can inhibit TCF transcription.

the actin cytoskeleton via the JNK pathway and filopodial extension [41, 49] (fig. 3). Activation of the filamin A-JNK axis also promotes lamellipodial formation [49] (fig. 3), perhaps by activating paxillin and focal adhesion kinase $[50,51]$ and reorientation of the microtubule-organising centre [49] (fig. 3). Thus, the Ror and PCP pathways cooperate at the level of the cytoskeleton to establish cell polarity, an essential requirement for cell division and directed cell and axon migration.

Wnt5a/Ror2 interactions also impinge on the Wnt/ $\beta$ catenin pathway. However, this activity appears to be dependent on the stimulating canonical Wnt and cell type. Wnt3a stimulation of TCF-mediated transcription is blocked by Wnt5a-Ror2 activation in HEK293 cells [39, 52, 53] (fig. 3), whereas Ror2 augments Wnt1-induced transcription but inhibits Wnt3a-induced transcription 
in U2OS osteosarcoma cells [38] (fig. 3). Thus, there is a complex regulatory crosstalk between these pathways. Ror2 is known to interact with several Fzs and forms a receptor complex under specific conditions [40, 54-56]. One explanation for these opposing activities may lie in the identity of the Fz receptor. However, there is also evidence that Ror can act independently of Fz. A recent study has shown that the $\mathrm{C}$ terminus of Dvl can bind Ror2, resulting in the inhibition of the Wnt/ $\beta$-catenin pathway [57]. Therefore, Dvl-mediated activation of the Wnt/ $\beta$-catenin pathway appears to be overruled by the Ror/Dvl negative feedback loop, at least in some contexts. Another point of intersection between Ror and the Wnt/ $\beta$-catenin pathway is CK1, a key component of the $\beta$-catenin destruction complex [58]. CK1 phosphorylates the $\mathrm{Fz}$ coreceptor, LRP5/6, reinforcing the interaction with axin, leading to stabilisation of $\beta$-catenin (reviewed in Angers and Moon [17]; fig. 1). CK1 $\varepsilon$ also binds Ror2 and activates Ror2 autophosphorylation [58]. In addition, Wnt5a binding initiates Ror2 tyrosine autophosphorylation and the activation of Src family kinases [52]. However, the kinase domain is not required for filopodial extension and migration [55]. How these different phosphorylation states are differentially regulated is still not well understood.

\section{The Non-Canonical Ryk Pathway}

The Ryk orthologue derailed (Drl) was initially identified as a chemorepulsive axon guidance receptor in the Drosophila nerve cord where its cognate ligand was identified as Wnt5 [59, 60]. It has since been shown to be required for synaptogenesis and memory and learning in the adult fly $[61,62]$. In vertebrates, more diverse roles are emerging for Ryk in a range of neurodevelopmental processes. In addition to chemorepulsive axon guidance [6366], Ryk is important for establishing planar polarity during neural tube development in the Xenopus embryo [67], differentiation of mouse neural progenitor cells $[68,69]$, specification of GABAergic neurons during mouse cortical development [70] and neuronal migration into the expanding cortical plate [71]. Although the function of Ryk is currently best understood with respect to its role in nervous system development, its widespread expression, both in developing tissues and in the adult, suggests that Ryk regulates many biological processes. This hypothesis is supported by the multiple developmental phenotypes apparent in Ryk loss-of-function mice, including skeletal, craniofacial and cardiac abnormalities [72].

Ryk is an atypical receptor tyrosine kinase due to its inactive tyrosine kinase domain [73-75]. Although it is clearly a member of the receptor tyrosine kinase superfamily, there are numerous amino acid substitutions in its kinase domain that render it 'kinase dead'. Interestingly, although human Ryk is kinase dead, it is able to activate the mitogen-activated protein kinase pathway [75], possibly via its interaction with the Src kinase family [76]. The Ryk extracellular domain is also unusual as it is considerably shorter than that found in other receptor tyrosine kinases [74]. The predominant features in the extracellular domain are the 2 leucine-rich motifs, which bear significant homology to the N-terminal domain of Wnt-inhibitory factor 1 (WIF-1) [77]. It has been shown that Ryk binds Wnts via these WIF-like domains [63].

Both the canonical (Wnt1, Wnt3) and non-canonical Wnts (Wnt5a, Wnt11) have been identified as Ryk ligands $[63,66,67]$, and as for the Ror receptors, Wnt5a/Ryk interactions have been most intensely studied $[63,65,78]$. Our knowledge of the Ryk signalling pathway comes largely from analysis of its axon guidance function. As guidance is dependent on establishing the correct polarity within the growth cone by the assembly and disassembly of the actin cytoskeleton, one would predict that Ryk signals through the non-canonical pathway. Indeed, Wnt5a/Ryk-mediated axon outgrowth and chemorepulsion have been shown to utilise the Wnt/Ca ${ }^{2+}$ pathway [64] (fig. 5). There is also evidence that Ryk may activate the Wnt/ $\beta$-catenin pathway by forming a coreceptor complex with Fz8 [66] (fig. 4).

Further light has been shed on the Ryk signal transduction pathway in Drosophila where chemorepulsion was found to be dependent on the Src non-receptor tyrosine kinase family. Src64B and Src42A are necessary for commissure formation, and loss of either kinase leads to disorganised commissures and longitudinal tract defects, a phenotype comparable to that seen in Wnt5 and derailed mutants [76]. It has been shown that Ryk and Src form a complex whose stability is dependent on Src activation and Drl phosphorylation [76] (fig. 5). Furthermore, the Wnt5/Drl/Src pathway does not affect TCF-dependent transcription. Together these data suggest that Drl does not signal via the $W n t / \beta$-catenin pathway but uses a novel Src-mediated non-canonical pathway. Whether mammalian Ryk also works through Src is unknown; however, the mammalian orthologues of Ryk and Src do form complexes [76], suggesting that Src signalling may be a universal requirement for Ryk-dependent chemorepulsion.

Recently, a novel mechanism for Ryk signal transduction has been uncovered in the early embryonic mouse cortex. The intracellular domain (ICD) of Ryk was shown to be cleaved by $\gamma$-secretase and then translocated to the 


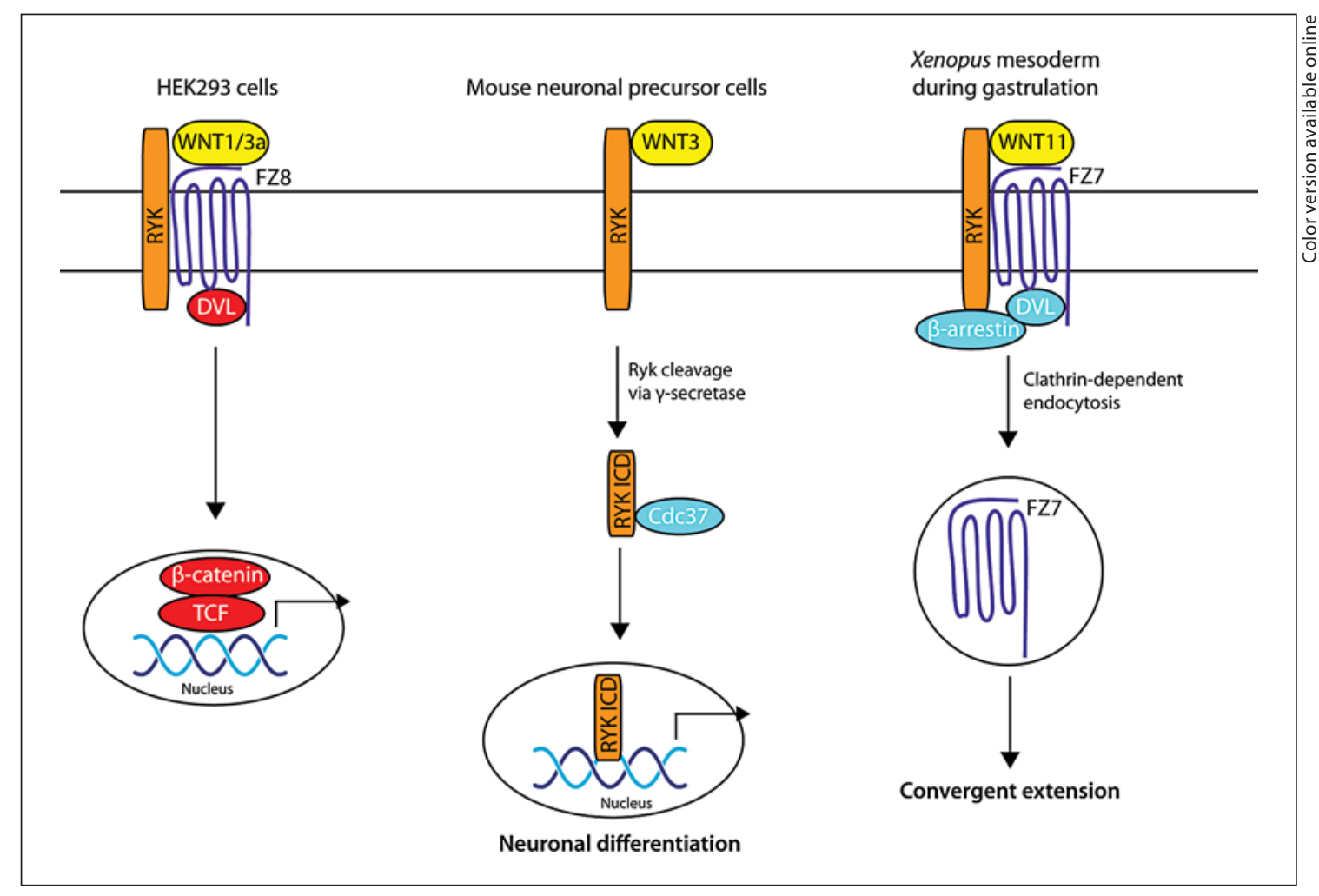

Fig. 4. Non-canonical Ryk signalling. In HEK 293 cells, Ryk forms a complex with Fz8 and Dvl, and Wnt1 or Wnt3a stimulation leads to TCF transcription. In mouse neuronal precursor cells, Wnt3 binds Ryk, and the Ryk intracellular domain is cleaved by $\gamma$-secretase. The Ryk intracellular domain is chaperoned to the nucleus by $\mathrm{Cdc} 37$ where it affects gene transcription regulating neuronal differentiation. In Xenopus mesoderm during gastrulation, Ryk forms a complex with Fz7, Dvl and $\beta$-arrestin. Wnt11 activation of this complex leads to clathrin-dependent endocytosis of $\mathrm{Fz}$ which regulates convergent extension. nucleus of newborn pyramidal projection neurons where it was postulated to promote the transcription of factors required for neuronal differentiation [68] (fig. 4). Wnt3 is necessary for Ryk ICD translocation but not cleavage, and the cochaperone protein $\mathrm{Cdc} 37$ is required for stabilisation of the Ryk ICD $[68,69]$ (fig. 4). Neither $\beta$-catenin stabilisation nor TCF-mediated transcription was observed after ICD translocation, indicating that Ryk signalling does not occur via the Wnt/ $\beta$-catenin pathway [68]. Conversely, Wnt3-mediated neuronal differentiation was shown to be dependent on the nuclear localisation of the Ryk ICD [68]. Clearly, there are multiple facets to Ryk signalling, and its interplay with the Wnt/ $\beta$ catenin pathway is complex.

The Ryk and Ror pathways share some intriguing commonalities. Both receptors bind canonical and noncanonical Wnts. Like Ror receptors, Ryk's favourite ligand is the non-canonical Wnt5a; however, other Wnts may come into focus as a deeper understanding of the biological roles of these receptors is revealed. Both path- ways cooperate with the PCP pathway to establish cell polarity, a fundamental requirement for directed cell and axon migration and asymmetric progenitor division. They accomplish these tasks by influencing the stability and orientation of the cytoskeletal network. Both pathways also modulate the $\mathrm{Wnt} / \beta$-catenin pathway, although the evidence in the case of Ryk needs to be bolstered. To date there is no evidence that the Ryk and Ror pathways interact, but given that they share ligands and some downstream effectors, it is unlikely that they operate independently. The above studies further suggest that the biological outcomes of Ryk and Ror signalling are likely to be context dependent.

\section{Wnt Signalling in Neural Tube Formation}

In vertebrate embryos, the neural tube, the first 3-dimensional structure of the CNS, comprises a pseudostratified neuro-epithelium surrounding a central lumen. 


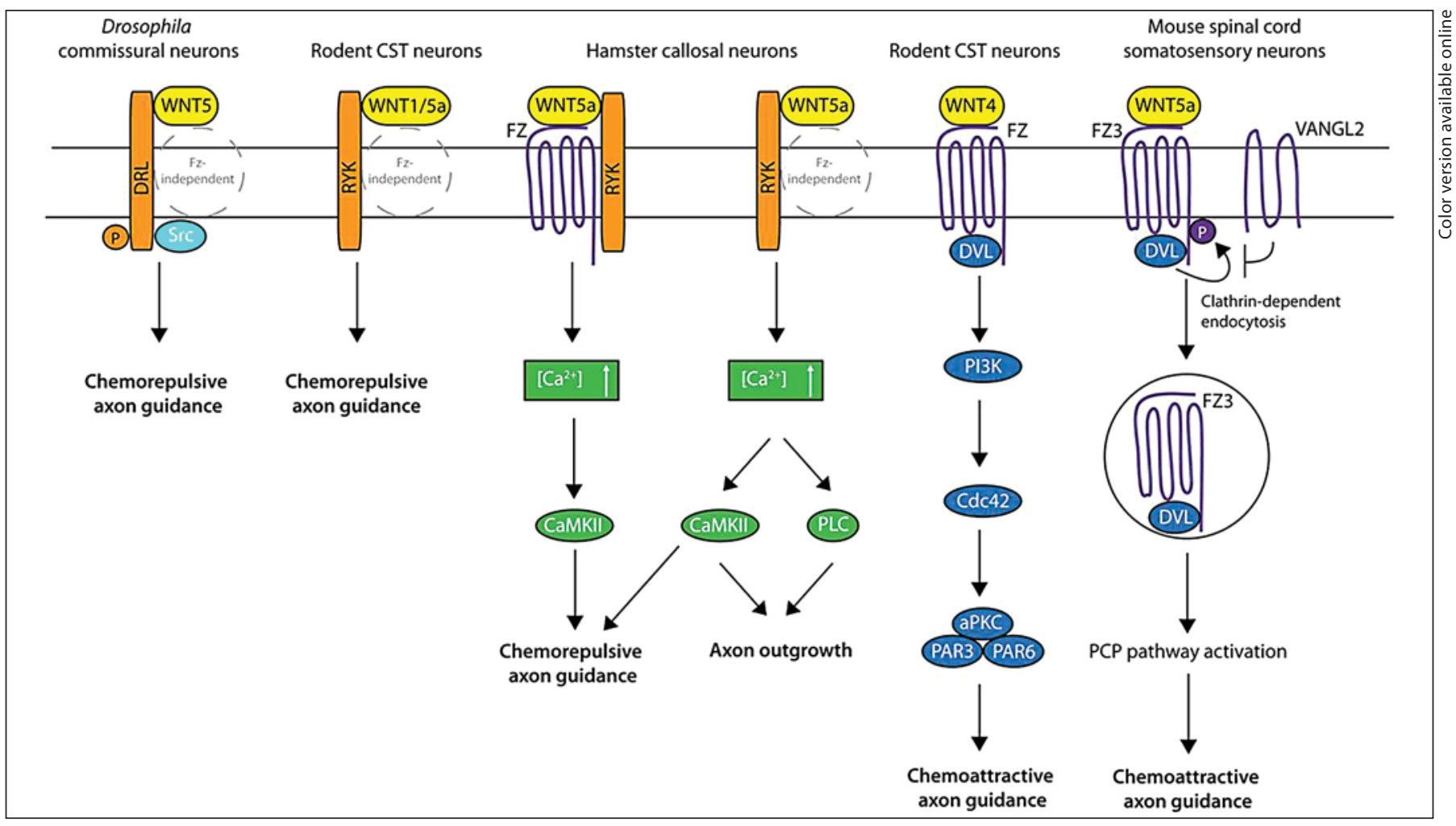

Fig. 5. Non-canonical Wnt signalling in axon guidance. In Drosophilia commissural neurons, Wnt5/Drl signalling via Src controls chemorepulsive axon guidance. Similarly, in rodent corticospinal tract (CST) neurons Wnt5a and Wntl control chemorepulsive axon guidance. These functions occur independently of Fz receptors. In contrast, in hamster callosal neurons, Wnt5a/Fz/Ryk signalling via the Wnt/Ca ${ }^{2+}$ pathway controls chemorepulsive axon guidance whereas Wnt/Ryk signalling alone, also via the $\mathrm{Ca}^{2+}$ pathway, controls axon outgrowth. Chemo-attractive axon guid-

This neuro-epithelium ultimately gives rise to all neural cell types in the CNS. The neural tube derives from a flat sheet of neuro-ectoderm (the neural plate) arising on the dorsal surface of the blastoderm at the end of gastrulation $[79,80]$. During Xenopus neurulation, the neuro-ectoderm and the underlying mesoderm migrate from the dorsolateral regions of the embryo towards the dorsal midline by mediolateral intercalation, a specialised form of migration where cells shuffle between each other while remaining in close contact [81] (fig. 2b). These synchronised cell movements contribute to the morphological process known as $\mathrm{CE}$ in which coordinated tissue movements shape the body axis by narrowing the embryo in the mediolateral direction and lengthening the anterioposterior axis $[82,83]$. As the neural plate approaches the midline, it elevates dorsally and the dorsal tips then fuse, leading to neural tube closure. The PCP pathway drives ance is mediated by Wnt/Fz interactions in rodent CST and spinal cord neurons. In rodent CST axons, Wnt4/Fz signalling via Cdc42 and the aPKC/Par3/Par6 complex regulates chemo-attraction. In mouse spinal cord commissural somatosensory neurons, Wnt5a/ Fz3 signalling stimulates Fz3-Dvl endocytosis to activate the PCP pathway and control chemo-attractive axon guidance. This process is regulated via Dvl-mediated Fz3 phosphorylation which is antagonised by Vangl2.

the medially directed movement of the neural folds [ 80 , 84-87] (fig. 2b), but not the elevation of the folds, which is regulated by the repulsive guidance molecule A receptor neogenin [88]. Mediolateral intercalation requires that the neuro-ectodermal cells polarise in a mediolateral orientation, which is established by the PCP pathway $[80,84,87,89,90]$. Failure of the PCP pathway abolishes mediolateral polarity, preventing migration towards the dorsal midline and neural fold fusion, resulting in devastating congenital malformations in which the brain and spinal cord are fully or partially open (anencephaly, craniorachischisis, spina bifida) [79].

\section{The PCP Pathway and CE}

In Xenopus and zebrafish, the interaction between non-canonical Wnt5a/Wnt11 and Fz3/Fz7 triggers a signalling cascade that induces mediolateral polarity in neu- 
ro-ectodermal cells during neural tube formation as well as in the gastrulating mesoderm $[22,32,91-93]$. The plasma membrane proteins Vang, Fmi (Celsrl) and the heparan sulphate proteoglycans knypek and syndecan 4 as well as the intracellular proteins $\mathrm{Dvl}$ and $\mathrm{Pk}$ are required for PCP-induced polarised cell intercalation [20, 22, 94]. Binding of Wnt concentrates $\mathrm{Fz}$ and $\mathrm{Dvl}$ to localised membrane subdomains [22]. Knypek and syndecan 4 are able to bind Wnts, and syndecan 4 can also bind $\mathrm{Fz}$ and Dvl. Therefore, these molecules may act to increase the local Wnt concentration at the receptor and/or to stabilise Fz-Dvl complexes at specific membrane subdomains. Vang interacts with $\mathrm{Pk}$ to negatively regulate $\mathrm{Dvl}$ activity (fig. 1). Pk antagonises the Dvl-Rho-Rac axis by preventing Dvl translocation to the membrane and can also promote its degradation. Thus, Vang-Pk activity dampens PCP-mediated GTPase activity, a function that would allow tight regulation over filopodial extension, thereby fine-tuning the response to the Wnt gradient. Vang and $\mathrm{Pk}$ are also able to activate JNK, a downstream effector of PCP signalling that triggers transcriptional activation. In Drosophila planar polarity, Fmi is responsible for homophilic cell-cell adhesion between the signalling and receiving cell (fig. 2) and interacts directly with the Fz cytoplasmic domain. In vertebrates, Fmi (Celsr) also has a cell adhesion function but does not appear to bind $\mathrm{Fz}$ [95]. Nonetheless, Fmi is required for efficient PCP signalling during vertebrate CE [96].

Daam1 is a downstream scaffold protein linking Dvl to RhoA (responsible for the formation of actin stress fibres) and Racl (responsible for the protrusion of lamellipodia), both of which are activated by directly binding to Dvl (fig. 1). The direct interaction of Dvl with RhoA and Rac is essential for Fz7-induced medially directed protrusion of lamellipodia. Furthermore, RhoA and Rac1 directly link the detection of Wnt at the cell surface to actin cytoskeleton remodelling and lamellipodial formation. Disruption of the PCP pathway in Xenopus embryos by expression of mutated forms of Wnt11, Fz7, Vang, Fmi, $P k$ or $D v l$ produces defective CE movements leading to the failure of neural tube closure. In $D v l$ mutants, neuroectodermal cells do not undergo mediolateral polarisation, which impedes intercalation-driven migration to the dorsal midline $[97,98]$. The result is a broader floorplate, which prevents apposition of the neural folds.

Mutations in the PCP components are also responsible for neural tube defects in mammals. The neural tube of mice homozygous for the looptail mutation in Vangl2 is completely open at the hindbrain and spinal cord levels (i.e. craniorachischisis) $[99,100]$ and mutations in Vangl1

Non-Canonical Wnt Signalling in Neural Migration and Vangl2 have been linked to neural tube defects in humans [101, 102]. Craniorachischisis-like phenotypes are also observed in the naturally occurring Celsrl mutant mouse and in knockout mice lacking Fz3, Fz6 or both Dvl1 and Dvl2 [97, 103-106]. Therefore, these phenotypes provide persuasive evidence that the core PCP pathway drives $\mathrm{CE}$ in the neuro-ectoderm in mammals. The ability of the PCP pathway to induce tissue polarity is reliant on the asymmetrical distribution of the core PCP complexes at the cell surface. Elegant studies in the cochlea have demonstrated that Vangl2, Fz3, Fz6 and Dvl2 are asymmetrically distributed in hair cells and that this distribution is lost in the Vangl2 mutant looptail [106-109]. Polarised localisation of $\mathrm{Fz}$ and Dvl has also been demonstrated in the converging neuro-ectoderm of the mouse [109]. Surprisingly this polarised localisation in the neuro-ectoderm was not perturbed in the absence of Vangl2 function as seen in the hair cells of the cochlea [108]. Why there should be a differential requirement for Vangl2 in these two converging tissues is unclear.

\section{The Wnt/Ca ${ }^{2+}$ Pathway and CE}

The Wnt/Ca ${ }^{2+}$ pathway participates in $\mathrm{CE}$ through PKC-mediated activation of the small GTPase Cdc42 [110], which promotes actin polymerisation and filopodial extension. In converging neuro-ectoderm and mesoderm Wnt5a-PKC stimulation of Cdc42 occurs independently of Dvl [110]. In parallel, Wnt5a-triggered $\mathrm{Ca}^{2+}$ release controls the ability of cells to adhere to each other during CE. Wnt $/ \mathrm{Ca}^{2+}$ signalling also antagonises Wnt $/ \beta$ catenin signalling through inhibition of both Dvl and TCF $[27,34-36]$. A similar mechanism occurs in zebrafish pipetail (wnt5) mutants where decreased $\mathrm{Ca}^{2+}$ leads to $\mathrm{CE}$ defects due to a lack of inhibition of Wnt/ $\beta$-catenin signalling [36].

\section{A Role for Ryk in CE}

A recent Xenopus study has uncovered a novel Rykdependent endocytosis mechanism regulating the levels of Fz7 on the cell surface, thereby modulating PCP pathway activity during neurulation [67]. Previous studies had shown that Wnt5a binding to Fz4 triggers receptor endocytosis through recruitment of the scaffold protein $\beta$-arrestin to Dvl [111]. The clathrin adaptor protein AP2 binds $\beta$-arrestin and also directly associates with Dvl and is required for Wnt5a-induced endocytosis via the clathrin-mediated pathway [26, 111]. In Xenopus the Dvl-AP2 interaction is required for Wnt4-triggered Fz4-Dvl internalisation, which leads to rapid degradation of the receptor in the lysosome [26]. Moreover, blocking the inter- 
nalisation of the Fz-Dvl complex prevents CE of the mesoderm during gastrulation. Kim et al. [67] have now shown that $\mathrm{Fz}$ endocytosis also requires Ryk. In parallel with the Wnt11/Fz7 interaction, binding of Wnt11 to Ryk recruits $\beta$-arrestin to Dvl, which associates with the Ryk cytoplasmic domain, leading to $\beta$-arrestin-mediated clathrin-dependent endocytosis of Fz7 [67] (fig. 4). Both receptors colocalise at the cell surface and in early endosomes, and removal of either receptor from the complex prevents internalisation. Therefore, endocytosis is codependent on Fz and Ryk activation by Wnt11 and provides a mechanism by which cell surface levels of the receptor complexes can be tightly regulated. Such a mechanism would ensure a finely tuned spatiotemporal response to the concentration of Wnt in the local environment, allowing appropriate cell polarisation within the mesoderm and neuro-ectoderm during CE.

\section{Ror Regulation of CE}

A role for Ror2 in Xenopus CE and neurulation was first revealed by Hikasa et al. [112] who demonstrated that overexpression of Ror2 inhibited CE by blocking PCP pathway activity. Ror-dependent inhibition required the interaction between Wnt11 and Ror2 and the presence of Fz7, suggesting that a trimeric complex was formed (fig. 3). Co-expression of dominant-negative Cdc42 partially rescued the Ror overexpression phenotype, indicating that Cdc42 may integrate incoming signals from both the PCP and Ror pathways (fig. 3). More recently, Ror has also been shown to activate Rac [113], another downstream target of PCP signalling. Thus, the small GTPases may lie at the centre of a complex network of non-canonical signalling cascades that work together to establish mediolateral polarity driving CE.

Given that PCP pathway activity is dependent on Wnt5a/Ryk-mediated Fz endocytosis, one might predict that Wnt5a/Ror interactions might also trigger endocytosis. To date this has not been shown in converging mesoderm or neuro-ectoderm. However, a recent study in HeLa3 cells has provided evidence to support this contention [113]. Wnt5a/Fz2 activation of Rac was found to be dependent on Fz2 internalisation via clathrin-mediated endocytosis (fig. 3). Moreover, knockdown of Rorl and Ror2 inhibited Fz2 endocytosis, suggesting that these receptors are required for internalisation. Due to the inability to demonstrate Ror colocalisation with Fz2 in early endosomes, it is not possible to conclude that Ror acts as a coreceptor to promote Fz2 capture in endocytosis. Instead, Ror may be playing an indirect role where it is not required to enter the endosomal compartment. Intrigu- ingly, the requirement for Dvl and $\beta$-arrestin in this process (fig. 3) points to the involvement of Ryk in promoting Fz2 endocytosis.

A second pathway by which Ror regulates CE in the Xenopus mesoderm during gastrulation has been uncovered by Schambony and Wedlich [114]. In the absence of the paraxial protocadherin XPAPC or Wnt5a, cells are unable to align in the mediolateral direction in a coordinated fashion. Instead individual cells move randomly within the tissue leading to an inability to form an intercalating sheet of cells - that is they fail to converge. Pathway mapping revealed that Wnt5a/Ror2 interactions activated JNK through Cdc42 and phosphatidylinositol-3-kinase (PI3K), resulting in c-jun- and ATF2-mediated upregulation of XPAPC (fig. 3). XPAPC then activates RhoA while inhibiting Rac1, thereby modulating the PCP pathway [115]. Thus, Wnt5a/Ror2 promote the transcription of a key polarity gene. Moreover, Wnt11, the PCP pathway activator, was not able to replace Wnt5a in this signalling cascade, indicating that the Wnt5a/Ror2 pathway is distinct from the Wnt11/PCP pathway [114]. Whereas Wnt5a/Ror 2 controls convergence by establishing coordinated mediolateral polarity throughout the sheet of cells, Wnt11/Fz establishes polarity at the level of the individual cell by promoting efficient lamellipodial protrusion. Inhibition of this pathway leads to loss of migration, preventing the tissue from extending perpendicularly to the mediolateral axis. Together these studies show that both pathways act in parallel to coordinate the complex set of cell-cell interactions required for effective $\mathrm{CE}$ of the mesoderm. Whether a similar pathway is important for $\mathrm{CE}$ in the neuro-ectoderm remains to be determined.

\section{Wnt5a, a Master Regulator of Non-Canonical Wnt Signalling?}

While the non-canonical Wnts, i.e. Wnt 4 and Wnt11, drive the establishment of mediolateral polarity through the PCP pathway, Wnt5a is emerging as a central modulator of CE via its ability to activate the other non-canonical pathways. Downstream effectors of the Wnt/Ca ${ }^{2+}$ pathway activated upon Wnt5a/Fz interactions work in parallel with the PCP pathway to achieve efficient CE. Wnt5a/Ryk and Wnt5a/Ror signalling are also required for neural tube closure and mesodermal CE in Xenopus embryos. These receptors directly modulate PCP signalling by forming complexes with $\mathrm{Fz}$ receptors at the cell surface or by sharing or influencing the activity of downstream effectors. Thus, Wnt5a may act as a master regulator to coordinate this complex network of non-canonical effectors. Given the high conservation in non-canonical 
signalling components across species, one would predict that these pathways would also be important drivers of neurulation in mammals. However, loss of Wnt5a, Ryk or Ror2 does not result in an open neural tube in the mouse, whereas CE defects are seen in the cochlea of Wnt5a-/and Ror2 $^{-/-}$mice $[116,117]$. Why this should be so is unclear. It should be noted, however, that in the mouse the neural plate consists of a single sheet of neuro-ectoderm cells. In contrast, the Xenopus neural plate comprises a superficial epithelium and a deeper mesenchyme-like layer, both of which need to become mediolaterally polarised. In addition, as the neural folds rise and fuse, these 2 layers must intercalate to form a single-layered neuro-epithelium. Therefore, neurulation in Xenopus is a more complex process and may require additional Wnt signalling pathways to regulate the central PCP pathway.

\section{Non-Canonical Wnt Signalling in Axon Guidance}

The correct navigation of axonal growth cones to their specific targets is essential for the establishment of the intricate network of axon projections found in the mature CNS. Directionality in axonal migration is determined by the response of the growth cone to the local environment through which it travels. Long-range guidance cues, secreted from intermediate or final targets, establish concentration gradients along the pathway of the exploring growth cone; in addition, membrane-bound or secreted short-range guidance cues are also employed to effect changes in the direction of growth cone migration along axon pathways and at specific choice points [118]. The intracellular signalling cascade initiated upon detection of the guidance cue by membrane-bound guidance receptors triggers dynamic rearrangements of the actin cytoskeleton within the growth cone. These rearrangements promote cycles of extension and retraction of filopodia and lamellipodia $[119,120]$, allowing the continual and spontaneous reassessment of the immediate environment by the growth cone. Given that non-canonical Wnt pathways promote polarised filopodial and lamellipodial activity by impinging directly on cytoskeletal dynamics, it is not surprising that they are major players in directing axonal navigation. Exploration of Wnt signalling in axon guidance has revealed essential roles for Fzs and Ryk in the formation of major axon tracts in vertebrates. To date there is no evidence that the Ror receptors participate in axon pathfinding in vertebrates but there are reports that the Caenorhabditis elegans orthologue CAM1 does have this function [121].

Non-Canonical Wnt Signalling in Neural Migration
Here, we focus on the interplay between Fz- and Rykmediated non-canonical pathways in axon navigation along the major axon tracts in the mammalian nervous system, the corpus callosum in the telencephalon, and the corticospinal tract (CST) and ascending somatosensory tract within the spinal cord. Guidance of axons within these tracts involves numerous molecular guidance systems $[122,123]$ including chemo-attractive cues such as netrin 1 and chemorepulsive cues such as Slit. Non-canonical Wnt signalling via the PCP and Ryk$\mathrm{Wnt} / \mathrm{Ca}^{2+}$ pathways acts in parallel with these guidance systems to ensure error-free axon pathfinding. These examples emphasise the absolute requirement for the correct interpretation of Wnt gradients by the migrating growth cones.

Navigation in the Developing Spinal Cord - The PCP Pathway and Ascending Somatosensory Axons

In the embryonic rodent spinal cord dorsally situated commissural somatosensory neurons project axons ventrally following chemo-attractive guidance cues, including netrin 1 and sonic hedgehog and then cross the floorplate [124-126]. On the contralateral side, these axons turn anteriorly and migrate to their targets in the brain. Anterior turning into the spinal cord is driven by a chemo-attractive Wnt4 anterior-high to posterior-low gradient detected by Fz3 on the postcrossing axons [127]. Wnt4/Fz3-mediated guidance involves the PI3K/atypical

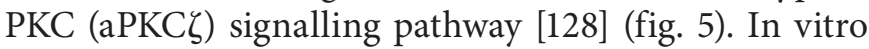
explant assays have shown that precrossing axons are unable to respond to Wnt4 [128]. However, upon overexpression of the catalytic subunit of PI3K, p110Y, these axons are attracted to Wnt4, demonstrating that PI3K is a key determinant of axonal responsiveness to the Wnt4 gradient. Upon Wnt/Fz binding, activation of PI3K leads to formation of the aPKC $\zeta / P a r 3 / P a r 6$ polarity complex, known to be downstream of $\mathrm{Cdc} 42$ and essential for the establishment of axodendritic polarity in neurons and apicobasal polarity in epithelia [for reviews, see 129-131] (fig. 5). The interrelationship between Wnt signalling (both canonical and non-canonical) and the apicobasal polarity machinery is complex, with many points of intersection, including Dvl and GSK3 $\beta$ [132]. Apicobasal signalling components operate upstream to suppress the non-canonical pathway and augment canonical Wnt signalling $[133,134]$. Conversely, Wnt/Fz can influence the localisation or transcription of polarity pathway components [135-137]. Interestingly, activation of the aPKC $/$ Par3/Par6 polarity complex has also been shown to lie downstream of Wnt5a in the induction of axonal differ- 
entiation in cultured hippocampal neurons [138]. Thus, the PI3K/aPKC $\zeta$ pathway is emerging as a divergent branch of non-canonical Wnt signalling able to coordinate distinct Wnt signalling cascades governing neuronal polarity, axon growth and pathfinding.

The anterior turning of commissural somatosensory axons in the spinal cord also requires Wnt5a, which is also expressed in an anterior-high to posterior-low gradient. In this system Wnt5a acts as a chemo-attractive guidance cue activating the PCP pathway by triggering internalisation of Fz3/Dvl complexes followed by JNK activation [23] (fig. 5). The ability of Fz3 to enter the endocytic pathway is strictly regulated by its level of phosphorylation. A negative feedback loop is initiated whereby activated Dvl prevents endocytosis by increasing Fz3 phosphorylation (fig. 5). Vangl2, at the cell surface, opposes this activity by reducing Fz3 phosphorylation (fig. 5), promoting another round of endocytosis. Vangl2 protein is enriched at the tips of filopodia and in patches of membrane where filopodia emerge. Therefore, Vangl2 is perfectly positioned to cell-autonomously restrict Fz3-mediated actin dynamics to the membrane of the gradient detectors (i.e. the filopodia) of the growth cone [23].

\section{Ryk, a Chemorepulsive Guidance Receptor}

The initial evidence that Ryk was an axon guidance receptor came from the Drosophila orthologue Drl. The Drosophila embryonic CNS comprises a brain and a ventral nerve cord, a structure that has served as a useful model for the study of axon fasciculation and axon guidance. The ventral nerve cord consists of two longitudinal axon tracts that contact the brain anteriorly and extend approximately halfway down the embryo's longitudinal axis. Communication between the two longitudinal tracts occurs via the anterior and posterior commissures within each body segment. $\mathrm{Drl}$ is expressed selectively in neurons whose axons cross the ventral nerve cord via the anterior commissure. In wild-type animals, axons from these neurons never cross through the posterior commissure, indicating the presence of a chemorepulsive cue surrounding this tract. However, in derailed mutants, anterior axons frequently project through this region [59]. Wnt5 is expressed in the posterior commissure and is the chemorepulsive ligand that prevents Drl-positive axons from entering [60] (fig. 5).

\section{Ryk and the Descending CST}

The CST is made up of axons originating from the pyramidal corticospinal projection neurons in layer 5 of the neocortex and projects along the length of the spinal cord.
CST motor axons project subcortically via the internal capsule and then posteriorly within the midbrain, cross at the pyramidal decussation in the ventral midbrain before projecting through the hindbrain and along the dorsal funiculus of the spinal cord [139]. Guidance of CST axons begins embryonically with axons first entering the spinal cord at postnatal day 0 (P0) in the mouse, with the remainder of CST axon guidance occurring postnatally.

Ryk-dependent chemorepulsion is required for the posteriorly directed migration of CST axons down the postnatal spinal cord in response to Wnt1 and Wnt5a gradients [65]. $R y k$ is expressed on layer $5 / 6$ neurons at P0 and on CST axons at P5 in the mouse, while Wnt1 and $W n t 5 a$ mRNAs are expressed along the trajectory of the descending CST axons in an anterior-high to posteriorlow gradient [65]. In vitro explant assays demonstrated that both Wnt1 and Wnt5a were able to repel P0 CST axons and that anti-Ryk antibodies blocked this effect. Similar results were observed in vivo where anti-Ryk antibodies blocked the posterior pathfinding of CST axons [65]. These data demonstrate a role for Ryk-mediated guidance of CST axons via Wnt1 and Wnt5a chemorepulsive gradients (fig. 5). This effect was shown to be specifc to Wnt1/Wnt5a/Ryk-mediated chemorepulsive guidance as Wnt4/Fz3 chemo-attraction was not affected by antiRyk antibodies [65].

In their study, Liu et al. [65] also found that secreted Fzrelated protein 2 did not block Wnt/Ryk-dependent posteriorly directed repulsion down the spinal cord, providing further evidence that Ryk functions independently of Fzs. In the Drosophila embryo, Drl was also found to signal independently of the $\mathrm{Fz}$ receptors and did not require $\mathrm{Dvl}$ to promote Wnt5-dependent chemorepulsion [60] (fig. 5), providing an early example of an Fz-independent non-canonical Wnt signalling pathway. Conversely, Ryk has been shown to bind $\mathrm{Fz} 8$ and $\mathrm{Dvl}$, suggesting that it can act as an Fz8 coreceptor [66] (fig. 4). Unfortunately, no direct evidence for binding between Fz8 and Ryk in the presence of Wntl was provided in this study. However, evidence was presented that Wnt/Ryk interactions result in the activation of the downstream target of the canonical Wnt pathway, the TCF transcription factor, suggesting that the Ryk signalling pathway may intersect with the canonical Wnt pathway upstream of TCF [66] (fig. 4). As this study was carried out in HEK293T cells, its relevance to Ryk-dependent chemorepulsive axon guidance is not clear.

\section{Ryk and Navigation across the Corpus Callosum}

Within the mammalian forebrain, the corpus callosum is the largest interhemispheric commissure, respon- 
sible for information transfer between the two cerebral hemispheres. This facilitates the coordinated brain activity present in mammals allowing for the mastery of skills including the performance of complex motor and behavioural tasks and language and communication skills. More than 50 different human congenital syndromes, often associated with mental retardation and epilepsy, have been described in which dysgenesis or agenesis of the corpus callosum occurs (reviewed in Paul et al. [140]). The corpus callosum is made up of axons from pyramidal callosal projection neurons situated in neocortical layers $2 / 3$ and 5 . From mouse embryonic day 15 (E15), callosal axons project ventrally, turn medially within the intermediate zone, and then approach the callosal midline. The majority of axons cross the midline between E16 and E17 and from E18 onwards, project dorsally, making homotypic connections in the contralateral hemisphere [140, 141].

$R y k$ is expressed on callosal projection neurons within the cortex and their axons as they project across the corpus callosum and into the contralateral hemisphere [63]. In the absence of $R y k$, callosal axons successfully cross the midline but fail to project into the contralateral hemisphere [63]. Thus, Ryk-mediated axon guidance is required specifically for postcrossing callosal axon guidance. Wnt5a is expressed in glial cell populations that surround the callosal midline and is responsible for Rykmediated chemorepulsion of postcrossing (E18) axons. Conversely, Ryk is not required for the guidance of precrossing (E16-E17) axons, but does promote their fasciculation [63].

It has generally been accepted that chemorepulsive guidance receptors (e.g. the semaphorin receptors, neuropilins/plexins) achieve their effect by causing the growth cone to stall once the chemorepellent gradient has been detected [142]. One intriguing puzzle highlighted by the chemorepulsive activity of Ryk in both the CST and corpus callosum is that the axons continue to grow through high levels of the Wnt chemorepellent. Studies from the Kalil laboratory have uncovered a dual activity for Ryk in callosal axon migration that provides an explanation for these apparently conflicting observations. Investigation of Ryk signalling in cortical neurons from P2 hamster sensorimotor cortex when cortical axons are entering the corpus callosum [143] revealed that 2 distinct but interconnected arms of the $\mathrm{Wnt} / \mathrm{Ca}^{2+}$ pathway are activated by Wnt5a (fig. 5). Upon bath application of recombinant Wnt5a, Ryk induced an increase in intracellular $\mathrm{Ca}^{2+}$ through the activation of cell surface transient receptor potential channels and from intracellular stores by activation of IP3 receptors on the endoplasmic reticulum [64]. This led to the activation of CaMKII and phospholipase $\mathrm{C}$ and a subsequent increase in the rate of axon outgrowth [64] (fig. 5). In contrast, using an in vitro guidance assay, Wnt5a-dependent chemorepulsive guidance was shown to require Ryk and an unidentified Fz, extracellular $\mathrm{Ca}^{2+}$ entry through transient receptor potential channels and activation of CaMKII [64], but IP3-mediated $\mathrm{Ca}^{2+}$ release was not involved (fig. 5). A later study using cortical slice cultures confirmed these findings in callosal axons actively navigating across the cortical midline [78]. Taken together these results invoke a model in which Ryk-dependent outgrowth and Ryk/Fz-dependent guidance act through distinct arms of the Wnt/Ca ${ }^{2+}$ pathway to coordinate axon growth and navigation at key decision points in developing axon tracts. As both guidance and growth require rearrangement of the cytoskeleton, it is not surprising that both arms intersect at CaMKII. However, pathway specificity is determined upstream by the involvement of IP3-mediated release of intracellular $\mathrm{Ca}^{2+}$ stores. It should be noted that no direct interaction between Ryk and $\mathrm{Fz}$ was demonstrated in this study. These findings lead to the novel hypotheses that Wnt/Ryk signalling is primarily responsible for axon outgrowth, whereas Ryk and Fz work together to promote chemorepulsive axon guidance.

Another intriguing observation from the study of Keeble et al. [63] was that despite the bilateral Wnt5a expression surrounding the callosal midline, wild-type callosal axons were not sensitive to the chemorepulsive activity of Wnt5a prior to crossing the midline. Lack of repulsive activity on the ipsilateral side, however, cannot be attributed to the absence of Ryk on ipsilateral axons as the $R y k^{-/}$axons exhibit a defasciculation phenotype as they approach the midline, indicating that Ryk is present on these axons. Therefore, the ability of cortical axons to respond to Wnt5a must be temporally regulated. Using an siRNA knockdown approach in hamster cortical slice cultures, Hutchins et al. [78] have shown that loss of Ryk decreases the growth rate of postcrossing callosal axons but has no effect on precrossing growth. Moreover, there was a concomitant decrease in the frequency of $\mathrm{Ca}^{2+}$ transients in postcrossing growth cones. In addition, transfection of a CaMKII inhibitor also disrupted growth and guidance in postcrossing but not precrossing axons. Together these observations implicate $\mathrm{Ca}^{2+}$ signalling, specifically dynamic $\mathrm{Ca}^{2+}$ fluxes, in the temporal regulation of growth cone responsiveness to Wnt5a. Since Ryk is present on both pre- and postcrossing axons, another regulatory mechanism must be in- 
volved in modulating $\mathrm{Ryk} / \mathrm{Ca}^{2+}$ activity. The obvious candidate is Fz3, which is known to be important for callosal axon growth and guidance $[105,106]$. Fz3 is crucial for the formation of numerous axon tracts within the developing forebrain implicating Fz3 as a key cortical axon guidance receptor $[105,106]$. In $\mathrm{Fz}^{-/-}$mice there is a reduction or complete absence of the corpus callosum, internal capsule (thalamocortical and corticothalamic projections), anterior commissure and cerebral peduncles (CST) $[105,106]$. Therefore, one hypothesis would be that Fz3 suppresses Wnt5a/Ryk induction of $\mathrm{Ca}^{2+}$ fluxes in precrossing axons.

A complex interplay between Ryk and Fz5 has been revealed during the formation of retinotectal topographic maps in the chick [144]. Retinal ganglion cell (RGC) axons express $R y k$ in a ventral-high to dorsal-low gradient across the retina. In contrast, $F z 5$ expression is equivalent on ventral and dorsal RGC axons. In the tectum $W n t 3$ is expressed in a medial-high to lateral-low gradient. On reaching the tectum, interstitial axon branches projecting from ventral RGC axons are repelled in a Rykdependent manner from the medial tectal domain expressing high levels of Wnt3, whereas Ryk activity is absent on dorsal RGC axonal branches in the lateral domain. Concomitantly, branches from dorsal RGC axons are guided via Wnt3/Fz5 chemo-attractive activity towards the lateral tectum. Therefore, a single Wnt gradient (Wnt3) directs Fz-dependent attraction of dorsal branches and Ryk-dependent repulsion of ventral branches.

\section{Conclusions}

In this review we have focussed on the interplay between the non-canonical Wnt receptors in two fundamental morphological processes essential to the viability of the embryo - CE and axon pathfinding in the embryonic CNS. However, the basic principles of Wnt signalling emphasised here are also relevant to the morphogenesis of most embryonic tissues. From the many studies discussed in this review, it is clear that the non-canonical pathways (Fz-, Ror-, Ryk-dependent pathways) do not operate in isolation. Instead, each pathway cooperates in the remodelling of the cytoskeleton, leading to the establishment of cell polarity, an essential requirement for cell division and directed cell and axon migration. All non-canonical pathways also interact with the $\beta$-catenin pathway, depending on the biological context. Throughout this review we have highlighted the complex network of pathway crosstalk be- tween Wnt signalling pathways. Dvl and Vangl have emerged as key nodes in the network. Dvl interacts with all the Wnt receptors (Fz, Ror, Ryk) at the membrane and is therefore perfectly positioned to regulate crosstalk between pathways. Vangl2 is also a central player in $\mathrm{Fz}$ - and Ror-dependent polarity pathways, although as yet there is no evidence that it is involved in Ryk signalling. Wnt5a is also emerging as a master regulator of non-canonical Wnt signalling due to its ability to bind all receptor families.

However, many basic questions remain to be answered. It is clear that we do not understand the nature of the interactions between Fzs, Ryk and Ror. In some experimental paradigms, especially in in vivo situations, these receptors have been shown to signal independently, whereas in biochemical studies, often in generic cell lines, coreceptor complexes have been identified. One explanation may be that receptor interactions are very dynamic in vivo, making it difficult to capture receptor complexes. Moreover, we have no insight into the rules governing receptor complex formation and disassembly. In addition, interactions with Dvl, Vang and other PCP core proteins have yet to be fully explored in the context of Ryk and Ror. These potential interactions may determine the make-up of the receptor complexes at the cell surface. A further puzzle is how the responses triggered by different Wnt receptor interactions are integrated at the network level, especially when the local environment contains multiple Wnts. The answer may lie in an emerging paradigm in which the most effective receptor signalling occurs within endocytic vesicles. Evidence is now accumulating that Wnt signalling requires $\mathrm{Fz}$ endocytosis. This process is dependent on other Wnt receptors such as Ryk, which recruits components of the endocytic machinery to $\mathrm{Fz}$ [67]. Wnt-driven endocytosis ensures that cell surface levels of receptor complexes are tightly regulated and provides a mechanism with which to finely tune spatiotemporal responses to the concentration of Wnt in the local environment. It is also possible that different Wnts or receptor complexes trigger internalisation through distinct endocytic compartments. This would allow divergent signalling cascades to occur in parallel.

One of the most intriguing questions, especially with respect to CNS development, is how the extracellular Wnt gradient is translated into the establishment of correct cellular or growth cone polarity and directed migration. We have only recently started to comprehend the behaviour of pathway components at the spatiotemporal level. Clues to this fundamental question in the context of planar cell polarity have recently been uncovered in the developing limb [21]. In this system, the local Wnt concen- 
tration at a given point in the gradient determines the extent of Vangl2 phosphorylation within the Wnt/Ror/ Vangl2 complex. The gradient of Vangl2 phosphorylation then translates into a corresponding gradient of Vangl2 activity, asymmetric distribution and polarity induction. This study therefore provides insight into the cellautonomous mechanism by which the current position of the cell within the Wnt gradient modulates the intensity of Wnt signal transduction. Vangl2 also appears to be a key player in the detection of Wnt gradients in the navigating growth cone. The observation that Vangl2 restricts Fz3 signal transduction to the tips of mature and nascent filopodia in the growth cone [23] provides an important insight into how the spatial response to Wnt in the local environment is generated. Again we have no idea how the interplay between Fz, Ryk, Ror and other core PCP proteins influences the interpretation of Wnt gradients. Nor do we understand how responses to differ- ent Wnt gradients, or gradients of other guidance or polarity cues (e.g. netrins, sonic hedgehog), are integrated. Intriguingly, distinct endocytic compartments may again be the key to sorting out these multiple polarising inputs.

Despite 25 years of intensive study, there remains much to discover about the intricacies of Wnt signalling. However, recent advances highlighted in this review have set the scene for a new wave of investigations that should shed light onto the most fundamental and enduring questions in Wnt signal transduction.

\section{Acknowledgements}

C.E.J.C. was supported by an Australian Postgraduate Award. H.M.C. was supported by a Queensland State Government Smart Futures Fellowship. We thank the National Health and Medical Research Council of Australia for financial support through the Project Grant scheme.

\section{References}

1 Adamska M, Degnan BM, Green K, Zwafink $>11$ Sawa H, Lobel L, Horvitz HR: The Cae$\mathrm{C}$ : What sponges can tell us about the evolution of developmental processes. Zoology 2011;114:1-10.

-2 Adamska M, Larroux C, Adamski M, Green K, Lovas E, Koop D, Richards GS, Zwafink C, Degnan BM: Structure and expression of conserved Wnt pathway components in the demosponge Amphimedon queenslandica. Evol Dev 2010;12:494-518.

3 Van Amerongen R, Nusse R: Towards an integrated view of Wnt signaling in development. Development 2009;136:3205-3214.

4 Budnik V, Salinas P: Wnt signaling during synaptic development and plasticity. Curr Opin Neurobiol 2011;21:151-159.

$>5$ Endo Y, Rubin JS: Wnt signaling and neurite outgrowth: insights and questions. Cancer Sci 2007;98:1311-1317.

$\checkmark 6$ Goodrich LV: The plane facts of PCP in the CNS. Neuron 2008;60:9-16.

7 Salinas PC, Zou Y: Wnt signaling in neural circuit assembly. Annu Rev Neurosci 2008; 31:339-358.

8 Silhankova M, Korswagen H: Migration of neuronal cells along the anterior-posterior body axis of C. elegans: Wnts are in control. Curr Opin Genet Dev 2007;17:320-325.

$>9$ Shimizu H, Julius MA, Giarré M, Zheng Z, Brown AM, Kitajewski J: Transformation by Wnt family proteins correlates with regulation of $\beta$-catenin. Cell Growth Differ 1997;8: 1349-1358.

10 Bhanot P, Brink M, Samos CH, Hsieh JC, Wang Y, Macke JP, Andrew D, Nathans J, Nusse R: A new member of the frizzled family from Drosophila functions as a Wingless receptor. Nature 1996;382:225-230. norhabditis elegans gene lin-17, which is required for certain asymmetric cell divisions, encodes a putative seven-transmembrane protein similar to the Drosophila Frizzled protein. Genes Dev 1996;10:2189-2197.

12 Yang-Snyder J, Miller JR, Brown JD, Lai CJ, Moon RT: A Frizzled homolog functions in a vertebrate Wnt signaling pathway. Curr Biol 1996;6:1302-1306.

13 Povelones M, Nusse R: The role of the cysteinerich domain of Frizzled in Wingless-Armadillo signaling. EMBO J 2005;24:3493-3503. domain is a ligand for Van Gogh/Stbm during nonautonomous planar cell polarity signaling. Dev Cell 2008;15:462-469.

15 Wang HY, Liu T, Malbon CC: Structurefunction analysis of Frizzleds. Cell Signal 2006;18:934-941.

16 Gao C, Chen Y-G: Dishevelled: the hub of Wnt signaling. Cell Signal 2010;22:717-727.

17 Angers S, Moon RT: Proximal events in Wnt signal transduction. Nat Rev Mol Cell Biol 2009; $10: 10$

18 Huang $\mathrm{H}, \mathrm{He} \mathrm{X}$ : Wnt/ $\beta$-catenin signaling: new (and old) players and new insights. Curr Opin Cell Biol 2008;20:119-125.

$19 \mathrm{Wu}$ J, Mlodzik M: A quest for the mechanism regulating global planar cell polarity of tissues. Trends Cell Biol 2009;19:295-305.

20 Wang Y, Nathans J: Tissue/planar cell polarity in vertebrates: new insights and new questions. Development 2007;134:647-658.

21 Gao B, Song H, Bishop K, Elliot G, Garrett L, English MA, Andre P, Robinson J, Sood R, Minami Y, Economides AN, Yang Y: Wnt signaling gradients establish planar cell po-
14 Wu J, Mlodzik M: The Frizzled extracellular larity by inducing Vangl2 phosphorylation through Ror2. Dev Cell 2011;20:163-176.

22 Roszko I, Sawada A, Solnica-Krezel L: Regulation of convergence and extension movements during vertebrate gastrulation by the Wnt/PCP pathway. Semin Cell Dev Biol 2009;20:986-997.

23 Shafer B, Onishi K, Lo C, Colakoglu G, Zou Y: Vangl2 promotes Wnt/planar cell polarity-like signaling by antagonizing Dvll-mediated feedback inhibition in growth cone guidance. Dev Cell 2011;20:177-191.

24 Wallingford J, Mitchell B: Strange as it may seem: the many links between Wnt signaling, planar cell polarity, and cilia. Genes Dev 2011;25:201-213.

25 Habas R, Kato Y, He X: Wnt/Frizzled activation of Rho regulates vertebrate gastrulation and requires a novel formin homology protein Daam1. Cell 2001;107:843-854.

26 Yu A, Rual JF, Tamai K, Harada Y, Vidal M, He X, Kirchhausen T: Association of Dishevelled with the clathrin AP-2 adaptor is required for Frizzled endocytosis and planar cell polarity signaling. Dev Cell 2007;12: 129-141.

27 Ishitani T, Kishida S, Hyodo-Miura J, Ueno N, Yasuda J, Waterman M, Shibuya H, Moon RT, Ninomiya-Tsuji J, Matsumoto K: The TAK1-NLK mitogen-activated protein $\mathrm{ki}$ nase cascade functions in the Wnt-5a/Ca ${ }^{2+}$ pathway to antagonize $\mathrm{Wnt} / \beta$-catenin signaling. Mol Cell Biol 2003;23:131-139.

28 Kühl M, Sheldahl LC, Malbon CC, Moon RT: $\mathrm{Ca}^{2+} /$ calmodulin-dependent protein kinase II is stimulated by Wnt and Frizzled homologs and promotes ventral cell fates in Xenopus. J Biol Chem 2000;275:12701-12711. 
-29 Sheldahl LC, Slusarski DC, Pandur P, Miller JR, Kühl M, Moon RT: Dishevelled activates $\mathrm{Ca}^{2+}$ flux, PKC, and CaMKII in vertebrate embryos. J Cell Biol 2003;161:769-777.

- 30 Weeraratna AT, Jiang Y, Hostetter G, Rosenblatt K, Duray P, Bittner M, Trent JM: Wnt5a signaling directly affects cell motility and invasion of metastatic melanoma. Cancer Cell 2002;1:279-288.

- 31 Lau PM, Zucker RS, Bentley D: Induction of filopodia by direct local elevation of intracellular calcium ion concentration. J Cell Biol 1999;145:1265-1275.

- 32 Heisenberg CP, Tada M, Rauch GJ, Saúde L, Concha ML, Geisler R, Stemple DL, Smith JC, Wilson SW: Silberblick/Wnt11 mediates convergent extension movements during zebrafish gastrulation. Nature 2000;405:76-81.

- 33 Tada M, Smith JC: Xwnt11 is a target of Xenopus brachyury: regulation of gastrulation movements via Dishevelled, but not through the canonical Wnt pathway. Development 2000;127:2227-2238.

- 34 Kühl M, Geis K, Sheldahl LC, Pukrop T, Moon RT, Wedlich D: Antagonistic regulation of convergent extension movements in Xenopus by $\mathrm{Wnt} / \beta$-catenin and $\mathrm{Wnt} / \mathrm{Ca}^{2+}$ signaling. Mechanisms Dev 2001;106:61-76.

- 35 Torres MA, Yang-Snyder JA, Purcell SM, De Marais AA, McGrew LL, Moon RT: Activities of the Wnt-1 class of secreted signaling factors are antagonized by the Wnt-5a class and by a dominant negative cadherin in early Xenopus development. J Cell Biol 1996; 133:1123-1137.

- 36 Westfall TA, Brimeyer R, Twedt J, Gladon J, Olberding A, Furutani-Seiki M, Slusarski DC: Wnt-5/pipetail functions in vertebrate axis formation as a negative regulator of Wnt/ $\beta$-catenin activity. J Cell Biol 2003;162: 889-898.

-37 Minami Y, Oishi I, Endo M, Nishita M: Rorfamily receptor tyrosine kinases in noncanonical Wnt signaling: their implications in developmental morphogenesis and human diseases. Dev Dyn 2009:239:1-15.

- 38 Billiard J, Way DS, Seestaller-Wehr LM, Moran RA, Mangine A, Bodine PVN: The orphan receptor tyrosine kinase Ror2 modulates canonical Wnt signaling in osteoblastic cells. Mol Endocrinol 2004;19:90-101.

- 39 Mikels AJ, Nusse R: Purified Wnt5a protein activates or inhibits $\beta$-catenin-TCF signaling depending on receptor context. PLoS Biol 2006;4:e115.

-40 Oishi I, Suzuki H, Onishi N, Takada R, Kani S, Ohkawara B, Koshida I, Suzuki K, Yamada G, Schwabe GC, Mundlos S, Shibuya H, Takada S, Minami Y: The receptor tyrosine kinase Ror2 is involved in non-canonical Wnt5a/JNK signalling pathway. Genes Cells 2003;11:645-654.

41 Nishita M, Yoo SK, Nomachi A, Kani S, Sougawa N, Ohta Y, Takada S, Kikuchi A, Minami Y: Filopodia formation mediated by receptor tyrosine kinase Ror2 is required for Wnt5a-induced cell migration. J Cell Biol 2006; 175:555-562.
42 Akbarzadeh S, Wheldon LM, Sweet SMM, Talma S, Mardakheh FK, Heath JK: The deleted in brachydactyly B domain of Ror2 is required for receptor activation by recruitment of Src. PLoS One 2008;3:e1873.

43 Liu Y, Ross JF, Bodine PVN, Billiard J: Homodimerization of Ror2 tyrosine kinase receptor induces 14-3-3 $\beta$ phosphorylation and promotes osteoblast differentiation and bone formation. Mol Endocrinol 2007;21: 3050-3061.

44 Liu Y, Rubin B, Bodine PVN, Billiard J: Wn$\mathrm{t} 5 \mathrm{a}$ induces homodimerization and activation of Ror2 receptor tyrosine kinase. J Cell Biochem 2008;105:497-502.

45 De Chiara TM, Kimble RB, Poueymirou WT, Rojas J, Masiakowski P, Valenzuela DM, Yancopoulos GD: Ror2, encoding a receptorlike tyrosine kinase, is required for cartilage and growth plate development. Nat Genet 2000;24:271-274.

46 Nomi M, Oishi I, Kani S, Suzuki H, Matsuda T, Yoda A, Kitamura M, Itoh K, Takeuchi S, Takeda K, Akira S, Ikeya M, Takada S, Minami Y: Loss of $m$ Rorl enhances the heart and skeletal abnormalities in mRor2-deficient mice: redundant and pleiotropic functions of $\mathrm{mRor} 1$ and $\mathrm{mRor} 2$ receptor tyrosine kinases. Mol Cell Biol 2001;21:8329-8335.

47 Takeuchi S, Takeda K, Oishi I, Nomi M, Ikeya M, Itoh K, Tamura S, Ueda T, Hatta T, Otani H, Terashima T, Takada S, Yamamura H, Akira S, Minami Y: Mouse Ror2 receptor tyrosine kinase is required for the heart development and limb formation. Genes Cells 2000;5:71-78.

-48 Yamaguchi TP, Bradley A, McMahon AP, Jones S: A Wnt5a pathway underlies outgrowth of multiple structures in the vertebrate embryo. Development 1999;126:12111223.

49 Nomachi A, Nishita M, Inaba D, Enomoto M, Hamasaki M, Minami Y: Receptor tyrosine kinase Ror2 mediates Wnt5a-induced polarized cell migration by activating c-Jun $\mathrm{N}$-terminal kinase via actin-binding protein filamin A. J Biol Chem 2008;283:2797327981.

50 Huang C, Rajfur Z, Borchers C, Schaller MD, Jacobson K: JNK phosphorylates paxillin and regulates cell migration. Nature 2003; 424:219-223.

51 Matsumoto S, Fumoto K, Okamoto T, Kaibuchi K, Kikuchi A: Binding of APC and dishevelled mediates Wnt5a-regulated focal adhesion dynamics in migrating cells. EMBO J 2010;29:1192-1204.

52 Enomoto M, Hayakawa S, Itsukushima S, Ren DY, Matsuo M, Tamada K, Oneyama C, Okada M, Takumi T, Nishita M, Minami Y: Autonomous regulation of osteosarcoma cell invasiveness by Wnt5a/Ror2 signaling. Oncogene 2009;28:3197-3208.

$53 \mathrm{Li} \mathrm{C}$, Chen H, Hu L, Xing Y, Sasaki T, Villosis M, Li J, Nishita M, Minami Y, Minoo P: Ror2 modulates the canonical Wnt signaling in lung epithelial cells through cooperation with Fzd2. BMC Mol Biol 2008;9:11.
4 Green JL, Inoue T, Sternberg PW: Opposing Wnt pathways orient cell polarity during organogenesis. Cell 2008;134:646-656.

55 Nishita M, Itsukushima S, Nomachi A, Endo M, Wang Z, Inaba D, Qiao S, Takada S, Kikuchi A, Minami Y: Ror2/Frizzled complex mediates Wnt5a-induced AP-1 activation by regulating Dishevelled polymerization. Mol Cell Biol 2010;30:3610-3619.

56 Yamamoto H, Oue N, Sato A, Hasegawa Y, Yamamoto H, Matsubara A, Yasui W, Kikuchi A: Wnt5a signaling is involved in the aggressiveness of prostate cancer and expression of metalloproteinase. Oncogene 2010; 29:2036-2046.

57 Witte F, Bernatik O, Kirchner K, Masek J, Mahl A, Krejci P, Mundlos S, Schambony A, Bryja V, Stricker S: Negative regulation of Wnt signaling mediated by CK1-phosphorylated Dishevelled via Ror2. FASEB J 2010;24: 2417-2426.

58 Kani S, Oishi I, Yamamoto H, Yoda A, Suzuki H, Nomachi A, Iozumi K, Nishita M, Kikuchi A, Takumi T, Minami Y: The receptor tyrosine kinase Ror2 associates with and is activated by casein kinase I $\varepsilon$. J Biol Chem 2004;279:50102-50109.

59 Bonkowsky JL, Thomas JB: Cell-type specific modular regulation of derailed in the Drosophila nervous system. Mech Dev 1999;82: 181-184.

60 Yoshikawa S, McKinnon RD, Kokel M, Thomas JB: Wnt-mediated axon guidance via the Drosophila Derailed receptor. Nature 2003;422:583-588.

61 Dura J-M, Taillebourg E, Preat T: The Drosophila learning and memory gene linotte encodes a putative receptor tyrosine kinase homologous to the human RYK gene product. FEBS Lett 1995;370:250-254.

62 Liebl FL, Wu Y, Featherstone DE, Noordermeer J, Fradkin L, Hing H: Derailed regulates development of the Drosophila neuromuscular junction. Dev Neurobiol 2008;68: 152-165.

-63 Keeble TR, Halford MM, Seaman C, Kee N, Macheda M, Anderson RB, Stacker SA, Cooper HM: The Wnt receptor Ryk is required for Wnt5a-mediated axon guidance on the contralateral side of the corpus callosum. J Neurosci 2006;26:5840-5848.

64 Li L, Hutchins B, Kalil K: Wnt5a induces simultaneous cortical axon outgrowth and repulsive axon guidance through distinct signaling mechanisms. J Neurosci 2009;29: 5873-5883.

65 Liu Y, Shi J, Lu C, Wang Z, Lyuksyutova A, Song X, Zou Y: Ryk-mediated Wnt repulsion regulates posterior-directed growth of corticospinal tract. Nat Neurosci 2005;8:11511159.

-66 Lu W, Yamamoto V, Ortega B, Baltimore D: Mammalian Ryk is a Wnt coreceptor required for stimulation of neurite outgrowth. Cell 2004;119:97-108. 
67 Kim G-H, Her J-H, Han J-K: Ryk cooperates with Frizzled 7 to promote Wnt11-mediated endocytosis and is essential for Xenopus laevis convergent extension movements. J Cell Biol 2008;182:1073-1082.

68 Lyu J, Yamamoto V, Lu W: Cleavage of the Wnt receptor Ryk regulates neuronal differentiation during cortical neurogenesis. Dev Cell 2008;15:773-780.

69 Lyu J, Wesselschmidt R, Lu W: Cdc37 regulates Ryk signaling by stabilizing the cleaved Ryk intracellular domain. J Biol Chem 2009; 284:12940-12948.

-70 Zhong J, Kim H-T, Lyu J, Yoshikawa K, Nakafuku M, Lu W: The Wnt receptor Ryk controls specification of GABAergic neurons versus oligodendrocytes during telencephalon development. Development 2011;138: 409-419.

-71 Kamitori K, Tanaka M, Okuno-Hirasawa T, Kohsaka S: Receptor related to tyrosine kinase RYK regulates cell migration during cortical development. Biochem Biophys Res Commun 2005;330:446-453.

72 Halford MM, Armes J, Buchert M, Meskenaite V, Grail D, Hibbs ML, Wilks AF, Farlie PG, Newgreen DF, Hovens CM, Stacker SA: Ryk-deficient mice exhibit craniofacial defects associated with perturbed Eph receptor crosstalk. Nat Genet 2000;25:414-418.

-73 Halford MM, Oates AC, Hibbs ML, Wilks AF, Stacker SA: Genomic structure and expression of the mouse growth factor receptor related to tyrosine kinases (Ryk). J Biol Chem 1999;11:7379-7390.

- 74 Hovens CM, Stacker SA, Andres AC, Harpur AG, Ziemiecki A, Wilks AF: Ryk, a receptor tyrosine kinase-related molecule with unusual kinase domain motifs. PNAS USA 1992;89:11818-11822.

-75 Katso RM, Russell RB, Ganesan TS: Functional analysis of H-Ryk, an atypical member of the receptor tyrosine kinase family. $\mathrm{Mol}$ Cell Biol 1999;19:6427-6440.

76 Wouda R, Bansraj M, De Jong A, Noordermeer J, Fradkin L: Src family kinases are required for WNT5 signaling through the Derailed/RYK receptor in the Drosophila embryoniccentralnervoussystem. Development 2008;135:2277-2287.

77 Patthy L: The WIF module. Trends Biochem Sci 2000;25:12-13.

78 Hutchins BI, Li L, Kalil K: Wnt/calcium signaling mediates axon growth and guidance in the developing corpus callosum. Dev Neurobiol 2011;71:269-283.

79 Copp AJ: Neurulation in the cranial region - normal and abnormal. J Anat 2005; 207:623-635.

$\$ 80$ Wallingford JB: Neural tube closure and neural tube defects: studies in animal models reveal known knowns and known unknowns. Am J Med Genet C Semin Med Genet 2005;135C:59-68.

81 Keller R, Davidson L, Edlund A, Elul T, Ezin M, Shook D, Skoglund P: Mechanisms of convergence and extension by cell intercalation. Philos Trans R Soc Lond B Biol Sci 2000;355:897-922.
82 Shih J, Keller R: Patterns of cell motility in the organizer and dorsal mesoderm of Xenopus laevis. Development 1992;116:915930.

-83 Shih J, Keller R: Cell motility driving mediolateral intercalation in explants of Xenopus laevis. Development 1992;116:901-914.

84 Elul T, Keller R: Monopolar protrusive activity: a new morphogenic cell behavior in the neural plate dependent on vertical interactions with the mesoderm in Xenopus. Dev Biol 2000;224:3-19.

85 Ezin AM, Skoglund P, Keller R: The midline (notochord and notoplate) patterns the cell motility underlying convergence and extension of the Xenopus neural plate. Dev Biol 2003;256:100-114.

86 Ezin AM, Skoglund P, Keller R: The presumptive floor plate (notoplate) induces behaviors associated with convergent extension in medial but not lateral neural plate cells of Xenopus. Dev Biol 2006;300:670-686.

87 Wallingford JB: Planar cell polarity, ciliogenesis and neural tube defects. Hum Mol Genet 2006;15:R227-R234.

88 Kee N, Wilson N, De Vries M, Bradford D, Key B, Cooper HM: Neogenin and RGMa control neural tube closure and neuroepithelial morphology by regulating cell polarity. J Neurosci 2008;28:12643-12653.

89 Davidson LA, Keller RE: Neural tube closure in Xenopus laevis involves medial migration, directed protrusive activity, cell intercalation and convergent extension. Development 1999;126:4547-4556.

90 Wallingford JB, Rowning BA, Vogeli KM, Rothbächer U, Fraser SE, Harland RM: Dishevelled controls cell polarity during Xenopus gastrulation. Nature 2000;405:81-85.

91 Djiane A, Riou J, Umbhauer M, Boucaut J, Shi D: Role of frizzled 7 in the regulation of convergent extension movements during gastrulation in Xenopus laevis. Development 2000;127:3091-3100.

-92 Keller R: Shaping the vertebrate body plan by polarized embryonic cell movements. Science 2002;298:1950-1954.

-93 Kilian B, Mansukoski H, Barbosa FC, Ulrich F, Tada M, Heisenberg CP: The role of Ppt/ Wnt5 in regulating cell shape and movement during zebrafish gastrulation. Mech Dev 2003;120:467-476.

-94 Seifert JRK, Mlodzik M: Frizzled/PCP signalling: a conserved mechanism regulating cell polarity and directed motility. Nat Rev Genet 2007;8:126-138.

95 Carreira-Barbosa F, Kajita M, Morel V, Wada H, Okamoto H, Martinez Arias A, Fujita Y, Wilson SW, Tada M: Flamingo regulates epiboly and convergence/extension movements through cell cohesive and signalling functions during zebrafish gastrulation. Development 2009;136:383-392.

96 Formstone CJ, Mason I: Combinatorial activity of Flamingo proteins directs convergence and extension within the early zebrafish embryo via the planar cell polarity pathway. Dev Biol 2005;282:320-335.
97 Hamblet NS, Lijam N, Ruiz-Lozano P, Wang J, Yang Y, Luo Z, Mei L, Chien KR, Sussman DJ, Wynshaw-Boris A: Dishevelled 2 is essential for cardiac outflow tract development, somite segmentation and neural tube closure. Development 2002; 129:5827-5838

98 Wallingford JB, Harland RM: Neural tube closure requires Dishevelled-dependent convergent extension of the midline. Development 2002;129:5815-5825.

-99 Kibar Z, Vogan KJ, Groulx N, Justice MJ, Underhill DA, Gros P: Ltap, a mammalian homolog of Drosophila Strabismus/Van Gogh, is altered in the mouse neural tube mutant Loop-tail. Nat Genet 2001;28:251255.

100 Murdoch JN, Doudney K, Paternotte C, Copp AJ, Stanier P: Severe neural tube defects in the loop-tail mouse result from mutation of $L p p 1$, a novel gene involved in floor plate specification. Hum Mol Genet 2001; 10:2593-2601.

101 Kibar Z, Torban E, McDearmid J, Reynolds A, Berghout J, Mathieu M, Kirillova I, De Marco P, Merello E, Hayes J, Wallingford J, Drapeau P, Capra V, Gros P: Mutations in VANGL1 associated with neuraltube defects. N Engl J Med 2007;356:14321437.

102 Lei Y, Zhang T, Li H, Wu B, Jin L, Wang H: VANGL2 mutations in human cranial neural-tube defects. N Engl J Med 2010;362: 2232-2235.

103 Curtin JA, Quint E, Tsipouri V, Arkell RM, Cattanach B, Copp AJ, Henderson DJ, Spurr N, Stanier P, Fisher EM, Nolan PM, Steel KP, Brown SDM, Gray IC, Murdoch JN: Mutation of Celsrl disrupts planar polarity of inner ear hair cells and causes severe neural tube defects in the mouse. Curr Biol 2003;13:1129-1133.

104 Etheridge SL, Ray S, Li S, Hamblet NS, Lijam N, Tsang M, Greer J, Kardos N, Wang J, Sussman DJ, Chen P, Wynshaw-Boris A: Murine Dishevelled 3 functions in redundant pathways with Dishevelled 1 and 2 in normal cardiac outflow tract, cochlea, and neural tube development. PLoS Genet 2008;4:e1000259.

105 Wang Y, Thekdi N, Smallwood PM, Macke JP, Nathans J: Frizzled-3 is required for the development of major fiber tracts in the rostral CNS. J Neurosci 2002;22:85638573.

106 Wang Y, Zhang J, Mori S, Nathans J: Axonal growth and guidance defects in Frizzled3 knock-out mice: a comparison of diffusion tensor magnetic resonance imaging, neurofilament staining, and genetically directed cell labeling. J Neurosci 2006;26:355-364.

107 Montcouquiol M, Sans N, Huss D, Kach J, Dickman J, Forge A, Rachel R, Copeland N, Jenkins N, Bogani D, Murdoch J, Warchol M, Wenthold R, Kelley M: Asymmetric localization of Vangl2 and Fz3 indicate novel mechanisms for planar cell polarity in mammals. J Neurosci 2006;26:5265-5275. 
108 Wang J, Mark S, Zhang X, Qian D, Yoo S-J, 122 Izzi L, Charron F: Midline axon guidance Radde-Gallwitz K, Zhang Y, Lin X, Collazo A, Wynshaw-Boris A, Chen P: Regulation of polarized extension and planar cell polarity in the cochlea by the vertebrate PCP pathway. Nat Genet 2005;37:980-985.

109 Wang Y, Guo N, Nathans J: The role of Frizzled 3 and Frizzled 6 in neural tube closure and in the planar polarity of inner-ear sensory hair cells. J Neurosci 2006;26:21472156.

110 Choi S-C, Han J-K: Xenopus Cdc42 regulates convergent extension movements during gastrulation through $\mathrm{Wnt} / \mathrm{Ca}^{2+}$ signaling pathway. Dev Biol 2002;244:342-357.

111 Chen W, ten Berge D, Brown J, Ahn S, Hu LA, Miller WE, Caron MG, Barak LS, Nusse R, Lefkowitz RJ: Dishevelled 2 recruits $\beta$-arrestin 2 to mediate Wnt5A-stimulated endocytosis of Frizzled 4. Science 2003;301:1391-1394.

112 Hikasa H, Shibata M, Hiratani I, Taira M: The Xenopus receptor tyrosine kinase Xror2 modulates morphogenetic movements of the axial mesoderm and neuroectoderm via Wnt signaling. Development 2002;129:5227-5239.

-113 Sato A, Yamamoto H, Sakane H, Koyama $\mathrm{H}$, Kikuchi A: Wnt5a regulates distinct signalling pathways by binding to Frizzled2. EMBO J 2009;29:41-54.

-114 Schambony A, Wedlich D: Wnt-5a/Ror2 regulate expression of XPAPC through an alternative noncanonical signaling pathway. Dev Cell 2007;12:779-792.

- 115 Unterseher F, Hefele JA, Giehl K, De Robertis EM, Wedlich D, Schambony A: Paraxial protocadherin coordinates cell polarity during convergent extension via Rho A and JNK. EMBO J 2004;23:3259-3269.

- 116 Qian D, Jones C, Rzadzinska A, Mark S, Zhang X, Steel KP, Dai X, Chen P: Wnt5a functions in planar cell polarity regulation in mice. Dev Biol 2007;306:121-133.

- 117 Yamamoto S, Nishimura O, Misaki K, Nishita M, Minami Y, Yonemura S, Tarui $\mathrm{H}$, Sasaki H: Cthrcl selectively activates the planar cell polarity pathway of Wnt signaling by stabilizing the Wnt-receptor complex. Dev Cell 2008;15:23-36.

-118 Song H, Poo M: The cell biology of neuronal navigation. Nat Cell Biol 2001;3:E81-E88.

-119 Conde C, Cáceres A: Microtubule assembly, organization and dynamics in axons and dendrites. Nat Rev Neurosci 2009;10: 319-332.

120 Dent EW, Gertler FB: Cytoskeletal dynamics and transport in growth cone motility and axon guidance. Neuron 2003;40:209-227.

- 121 Kennerdell JR, Fetter RD, Bargmann CI: Wnt-Ror signaling to SIA and SIB neurons directs anterior axon guidance and nerve ring placement in C. elegans. Development 2009;136:3801-3810. and human genetic disorders. Clin Genet 2011;80:226-234.

123 Kolodkin AL, Tessier-Lavigne M: Mechanisms and molecules of neuronal wiring: a primer. Cold Spring Harb Perspect Biol 2011;3:a001727.

124 Charron F, Stein E, Jeong J, McMahon AP, Tessier-Lavigne M: The morphogen Sonic hedgehog is an axonal chemoattractant that collaborates with Netrin-1 in midline axon guidance. Cell 2003;113:11-23.

125 Kennedy TE, Serafini T, de la Torre JR, Tessier-Lavigne M: Netrins are diffusible chemotropic factors for commissural axons in the embryonic spinal cord. Cell 1994;78: 425-435.

126 Serafini T, Colamarino SA, Leonardo ED, Wang H, Beddington R, Skarnes WC, Tessier-Lavigne M: Netrin-1 is required for commissural axon guidance in the developing vertebrate nervous system. Cell 1996; 87:1001-1014.

127 Lyuksyutova A, Lu C, Milanesio N, King L, Guo N, Wang Y, Nathans J, Tessier-Lavigne M, Zou Y: Anterior-posterior guidance of commissural axons by Wnt-Frizzled signaling. Science 2003;302:19841988.

128 Wolf AM, Lyuksyutova AI, Fenstermaker AG, Shafer B, Lo CG, Zou Y: Phosphatidylinositol-3-kinase-atypical protein $\mathrm{ki}$ nase $\mathrm{C}$ signaling is required for Wnt attraction and anterior-posterior axon guidance. J Neurosci 2008;28:3456-3467.

129 Goldstein B, Macara IG: The PAR proteins: fundamental players in animal cell polarization. Dev Cell 2007;13:609-622.

130 Macara IG: Parsing the polarity code. Nat Rev Mol Cell Biol 2004;5:220-231.

131 Ohno S: Intercellular junctions and cellular polarity: the PAR-aPKC complex, a conserved core cassette playing fundamental roles in cell polarity. Curr Opin Cell Biol 2001;13:641-648.

132 Zhou F, Zhou J, Dedhar S, Wu Y, Snider W: NGF-induced axon growth is mediated by localized inactivation of GSK-3 $\beta$ and functions of the microtubule plus end binding protein APC. Neuron 2004;42: 897-912.

133 Ossipova O, Dhawan S, Sokol S, Green JBA: Distinct PAR-1 proteins function in different branches of Wnt signaling during vertebrate development. Dev Cell 2005;8:829841.

134 Sun TQ, Lu B, Feng JJ, Reinhard C, Jan YN, Fantl WJ, Williams LT: PAR-1 is a Dishevelled-associated kinase and a positive regulator of Wnt signalling. Nat Cell Biol 2001; 3:628-636.

135 Dollar GL, Weber U, Mlodzik M, Sokol SY: Regulation of Lethal giant larvae by Dishevelled. Nature 2005;437:1376-1380.
136 Malliri A, Rygiel TP, van der Kammen RA, Song J-Y, Engers R, Hurlstone AFL, Clevers H, Collard JG: The Rac activator Tiam1 is a Wnt-responsive gene that modifies intestinal tumor development. J Biol Chem 2006; 281:543-548.

137 Tao W, Pennica D, Xu L, Kalejta RF, Levine AJ: Wrch-1, a novel member of the Rho gene family that is regulated by Wnt- 1 . Genes Dev 2001;15:1796-1807.

138 Zhang X, Zhu J, Yang G-Y, Wang Q-J, Qian L, Chen Y-M, Chen F, Tao Y, Hu H-S, Wang T, Luo Z-G: Dishevelled promotes axon differentiation by regulating atypical protein kinase C. Nat Cell Biol 2007;9:743-754.

139 Canty AJ, Murphy M: Molecular mechanisms of axon guidance in the developing corticospinal tract. Prog Neurobiol 2008; 85:214-235.

140 Paul LK, Brown WS, Adolphs R, Tyszka JM, Richards LJ, Mukherjee P, Sherr EH: Agenesis of the corpus callosum: genetic, developmental and functional aspects of connectivity. Nat Rev Neurosci 2007;8:287299.

141 Richards L: Axonal pathfinding mechanisms at the cortical midline and in the development of the corpus callosum. Braz J Med Biol Res 2002;35:1431-1439.

142 Kitsukawa T, Shimizu M, Sanbo M, Hirata T, Taniguchi M, Bekku Y, Yagi T, Fujisawa H: Neuropilin-semaphorin III/D-mediated chemorepulsive signals play a crucial role in peripheral nerve projection in mice. Neuron 1997;19:995-1005.

143 Reh T, Kalil K: Development of the pyramidal tract in the hamster. I. A light microscopic study. J Comp Neurol 1981;200:55-67.

144 Schmitt AM, Shi J, Wolf AM, Lu C-C, King LA, Zou Y: Wnt-Ryk signalling mediates medial-lateral retinotectal topographic mapping. Nature 2005;439:31-37.

\section{Note Added in Proof}

Further evidence of Ryk-mediated activation of the Wnt/ $\beta$-catenin pathway has recently been shown. This is dependent on interaction of Ryk with the E3 ubiquitin ligase, Mindbomb 1, downstream of Wnt3a activation of Ryk.

\section{Reference}

Berndt JD, Aoyagi A, Yang P, Anastas JN, Tang L, Moon RT: Mindbomb 1, an E3 ubiquitin ligase, forms a complex with RYK to activate Wnt/ $\beta$-catenin signaling. J Cell Biol 2011;194:737-750. 